\title{
HDlive in the Assessment of Gynecologic Tumors
}

\author{
${ }^{1}$ Kenji Kanenishi, ${ }^{2}$ Sarah Cajusay-Velasco, ${ }^{3}$ Masato Mashima, ${ }^{4}$ Tamaki Tanaka, ${ }^{5}$ Uiko Hanaoka, ${ }^{6}$ Toshiyuki Hata
}

\begin{abstract}
We present the latest HDlive images of uterine and adnexal tumors. Evaluation of these tumors with conventional twodimensional (2D) sonography has been the standard procedure for morphologic assessment, but the introduction of threedimensional (3D), power Doppler and other recent modalities has been of great help in providing more specific details, especially in characterizing malignancy. HDlive is the latest ultrasound modality that enhances 3D and four-dimensional images. Several different gynecologic tumors were assessed using HDlive in this study. HDlive can provide realistic features of the inner surfaces and contents of tumors which are very similar to the gross specimens. An accurate characterization of gynecologic tumors is important when deciding on clinical management options. Therefore, HDlive may be a valuable tool in adjunct to other imaging modalities to achieve an accurate preoperative diagnosis.
\end{abstract}

Keywords: 2D ultrasound, 3D ultrasound, Inversion mode, HDlive, Uterine tumor, Adnexal tumor, Hydatidiform mole.

How to cite this article: Kanenishi $\mathrm{K}$, Cajusay-Velasco S, Mashima M, Tanaka T, Hanaoka U, Hata T. HDlive in the Assessment of Gynecologic Tumors. Donald School J Ultrasound Obstet Gynecol 2014;8(4):410-427.

Source of support: Nil

Conflict of interest: None

\section{INTRODUCTION}

Ultrasound has been the foundation for the evaluation of gynecologic tumors, such as uterine fibroids, endometrial thickness, local extent of endometrial cancer, and the differentiation of benign from malignant adnexal tumors. An accurate characterization of gynecologic tumors is very important when deciding on a suitable management strategy. The use of two-dimensional (2D) ultrasound was at the center of diagnostic evaluation, and evolution

\footnotetext{
${ }^{1}$ Associate Professor, ${ }^{2}$ Research Fellow, ${ }^{3,4}$ Senior Resident

${ }^{5}$ Senior Assistant Professor, ${ }^{6}$ Professor and Chairman

${ }^{1-6}$ Department of Perinatology and Gynecology, Kagawa University Graduate School of Medicine, Japan

Corresponding Author: Toshiyuki Hata, Professor and Chairman, Department of Perinatology and Gynecology, Kagawa University Graduate School of Medicine, 1750-1 Ikenobe, Miki Kagawa 761-0793, Japan, Phone: +81-0878912174, e-mail: toshi28@med.kagawa-u.ac.jp
}

to three- (3D) and four-dimensional (4D) ultrasound and other modalities set a higher standard in clinical management and in the field of gynecologic research.

The latest innovation, HDlive, is primarily used for viewing the gross fetal appearance, giving a realistic picture because of its virtual light source and availability of skin-like colors. ${ }^{1}$ Many studies have shown its significance in the evaluation of different fetal anomalies. ${ }^{2-5}$ Now, HDlive is gradually being introduced into the assessment of some gynecologic tumors, showing more realistic images which are very similar to the actual macroscopic specimens. ${ }^{6,7}$

This review presents HDlive images of various gynecologic tumors, describes its features, and discuss how to separate benign from malignant tumors.

\section{UTERINE TUMOR}

Abnormalities of the uterine corpus are usually the most problematic, causing symptoms such as pain and bleeding. Ultrasonography as the diagnostic method of choice can identify lesions within the uterus their extent in different layers or nearby structures and possible complications. With the enhancement of transvaginal probes and availability of different types of software that enhance images, we have greater opportunities to evaluate uterine lesions thoroughly.

\section{Hydatidiform Mole}

The 'snow storm' pattern is a classic 2D sonographic feature of a complete hydatidiform mole usually seen in the second trimester. ${ }^{8}$ Early-stage nonhydrophic moles vary in presentation because the vesicles are poorly developed (Fig. 1A). ${ }^{9}$ Hence, the diagnosis of hydatidiform mole in the first trimester is difficult. Other modalities may be helpful such as HD-flow for evaluation of its vascularization (Fig. 1B) ${ }^{9}$ HDlive can clearly depict a smooth, lobulated masses in the uterine cavity (Fig. 2). It can show minute structures such as small, irregular, cystic spaces inside the masses (Fig. 3). ${ }^{9}$

\section{Submucosal Fibroma}

It is the most common benign uterine tumor at reproductive age. ${ }^{10}$ A submucosal fibroma usually causes heavy menstrual bleeding. HDlive can clearly depict 

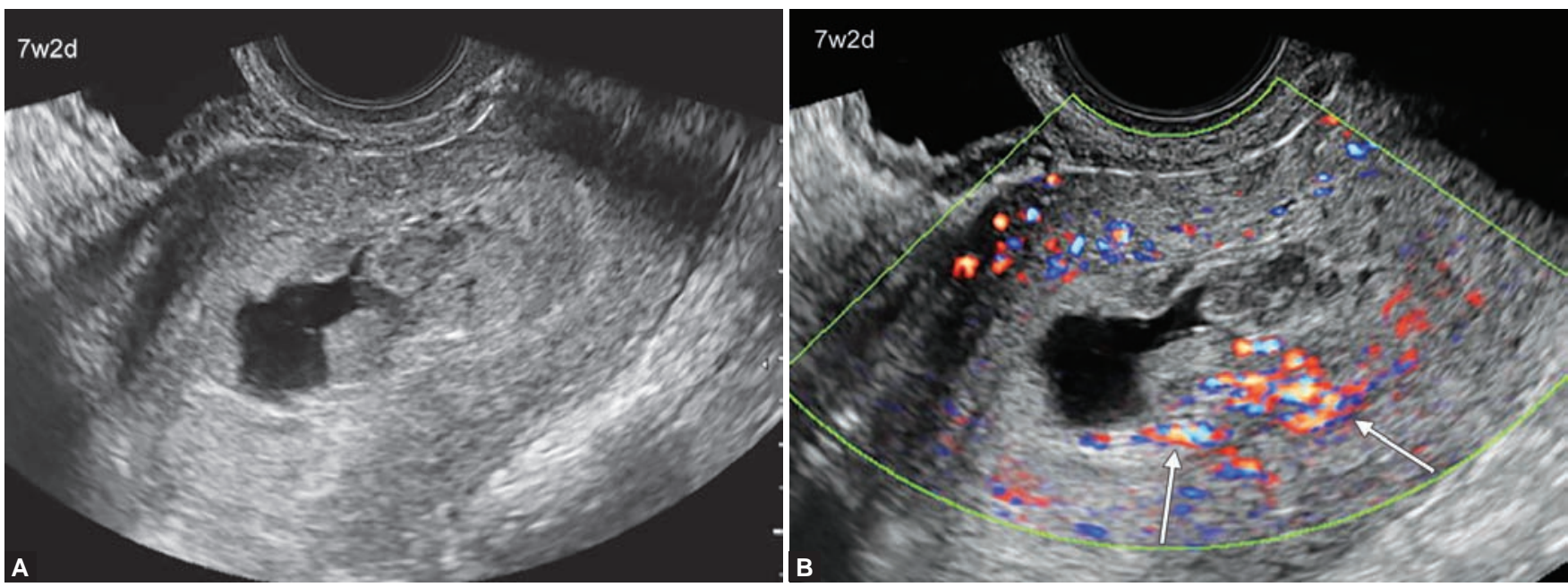

Figs 1A and B: Two-dimensional (2D) sonographic (A) and HD-flow (B) images of an early-stage nonhydropic mole at 7 weeks and 2 days of gestation. 2D sonography reveals massive, lobulated, and mixed masses and intrauterine anechoic fluid collection (A) HD-flow shows feeder vessels at the base of homogeneous, lobulated masses (arrows) (B) (Courtesy: Reprinted with permission from Hata T et al) ${ }^{9}$
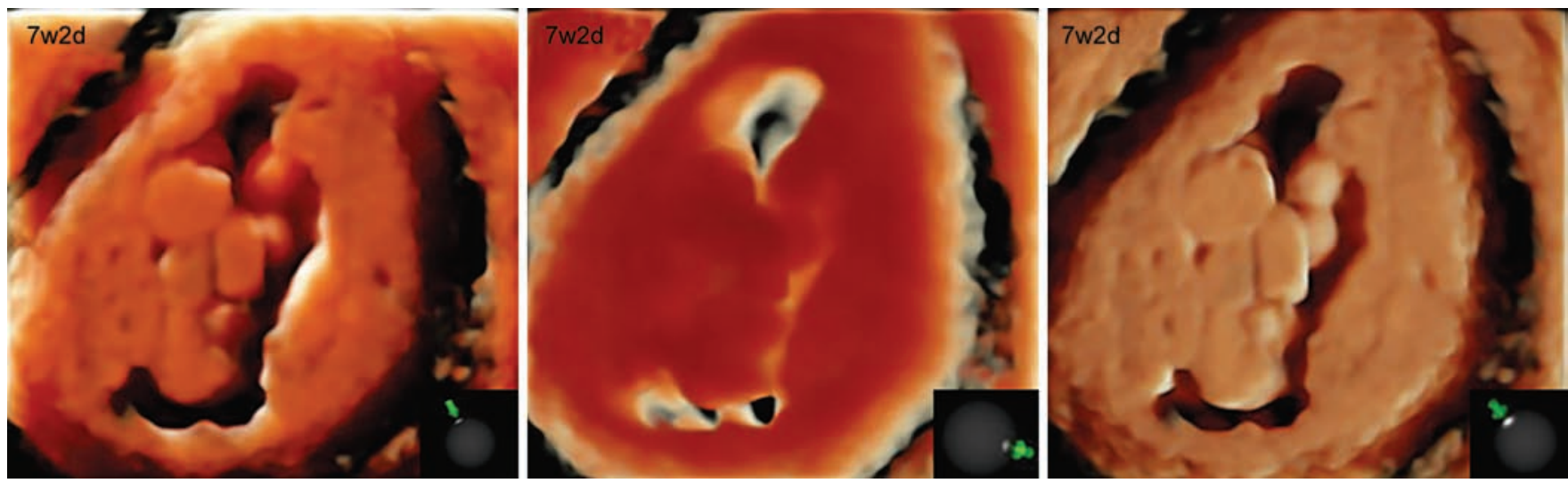

Fig. 2: HDlive images with different directions of the light source (lower right corner) of an early-stage nonhydropic mole at 7 weeks and 2 days of gestation. Smooth, lobulated masses can be clearly identified using HDlive (Courtesy: Reprinted with permission from Hata T et al) ${ }^{9}$
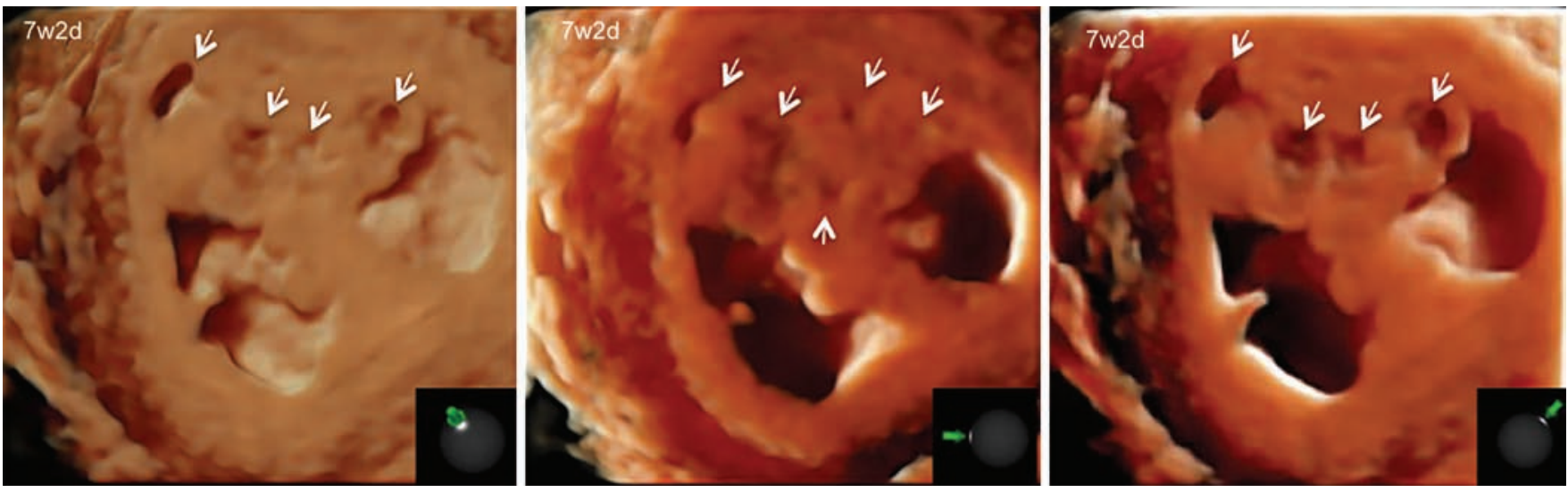

Fig. 3: HDlive images with different directions of the light source (lower right corner) of an early-stage nonhydropic mole at 7 weeks and 2 days of gestation. Small, irregular, cystic spaces inside the masses can be noted (arrows) (Courtesy: Reprinted with permission from Hata T et al) ${ }^{9}$

the anatomical location of a submucosal fibroma (Fig. 4). Localization of the stalk and its proximity to the internal os are very clear.

\section{Mesenchymal Tumor of the Uterus}

Mesenchymal tumor of the uterus other than fibroids is rare. ${ }^{11}$ Conventional $2 \mathrm{D}$ sonographic imaging might be 

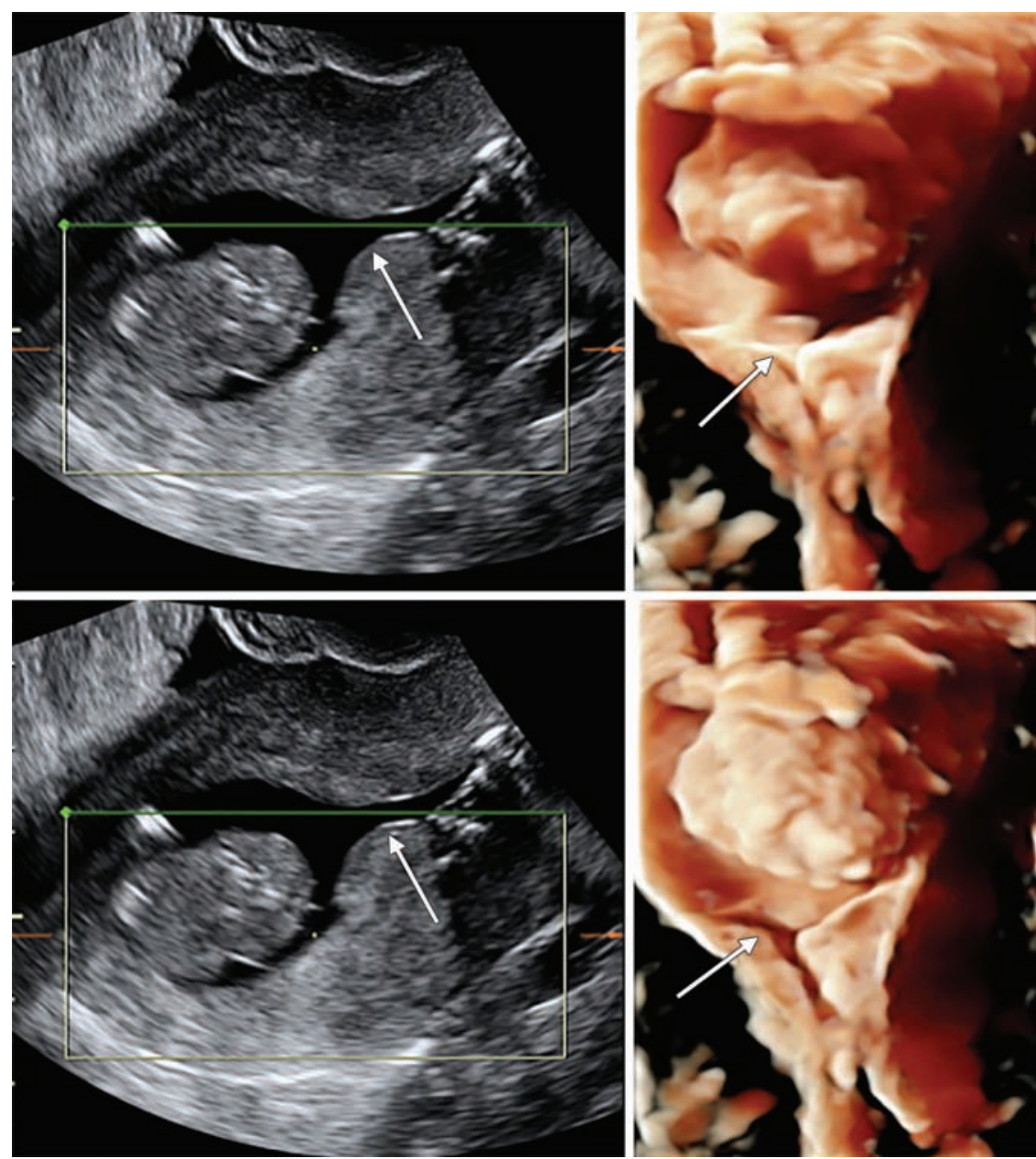

Fig. 4: HDlive images of a submucosal fibroma with saline infusion sonohysterography. Arrows indicate the internal OS
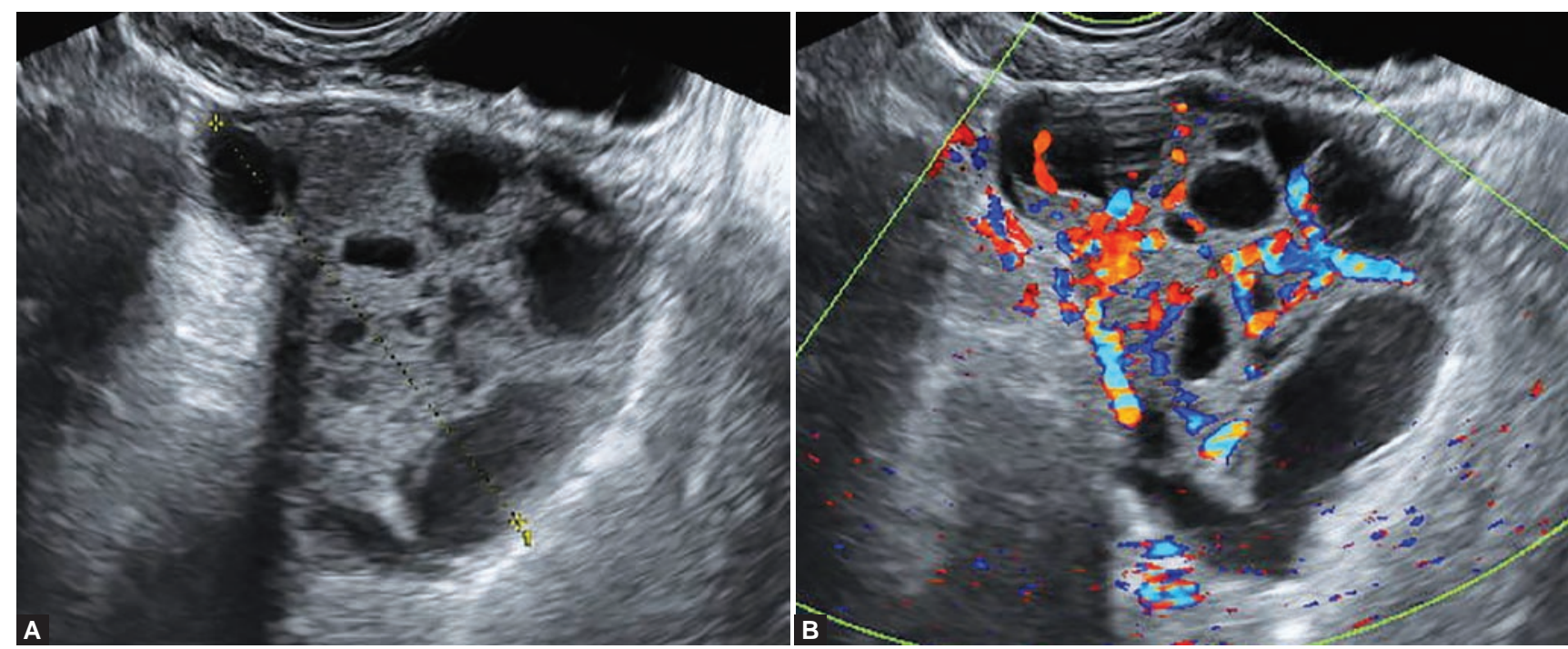

Figs 5A and B: Mesenchymal tumor of the uterus: $(A)$ two-dimensional sonographic image and (B) two-dimensional color Doppler ultrasound image

misleading for diagnosis, showing features very similar to those of ovarian tumors (Fig. 5A). 2D color Doppler shows abundant blood flow inside the tumor (Fig. 5B). HDlive can depict a cystic-like tumor (Fig. 6), similar to a gross specimen (Figs 7A and B).

\section{OVARIAN TUMOR}

Ovarian cancer is the leading cause of death among gynecologic malignancies. ${ }^{12}$ The development of ultrasound from 2D to 3D sonographic evaluation has been of considerable help in diagnosis at an early stage. ${ }^{13}$ 


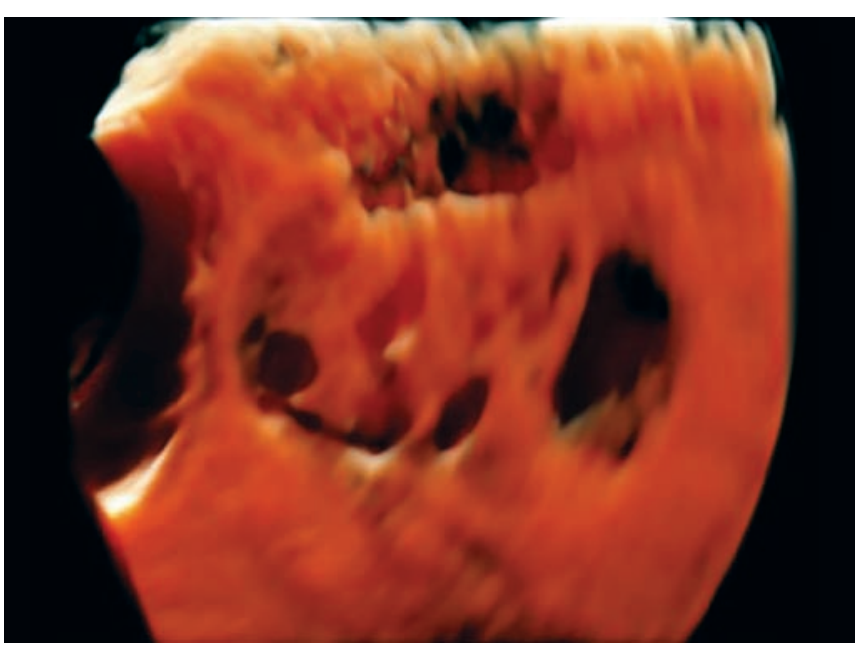

Fig. 6: HDlive image of a mesenchymal tumor

Using 2D sonography, the diagnosis of an ovarian tumor based on 'pattern recognition' is enhanced using 3D sonography with the following criteria: irregular thick septa, irregular papillary projections, mostly solid tumor, high echogenicity and irregular inner wall. ${ }^{13-15}$ With the latest HDlive, a precise picture of an ovarian tumor is produced which is very similar to macroscopic specimens. Differentiation between benign and malignant tumors is becoming more accurate.

\section{Simple Cyst}

Occurring at the rate of about 5 to $17 \%$, simple cyst of the ovary is very common. ${ }^{16}$ Regarding $2 \mathrm{D}$ sonographic findings, it is thin-walled, unilocular and sonoluscent. HDlive enhances a $2 \mathrm{D}$ sonographic image showing a smooth wall and smooth inner surface (Figs 8 and 9).

\section{Chocolate Cyst}

Also known as endometrioma, it usually appears as a unilocular cyst with ground glass echogenicity of cystic fluid. ${ }^{17}$ A 2D sonographic image shows a thin-walled structure with diffuse low-level echoes, and with some hyperechoic echoes in the wall (Fig. 10). ${ }^{6}$ HDlive clearly depicts the smooth wall and inner surface with numerous tiny projections (Fig. 11). ${ }^{6}$ These tiny projections are blood clots which are adherent to the wall.

\section{Benign Cystic Teratoma}

2D sonographic findings of a benign cystic teratoma vary because of its numerous internal echogenic foci, which represent its components: epithelium, hair, fat and teeth (Figs 12 and 13). ${ }^{12,18}$ One of the characteristics that differentiate it from malignancy is its vascularity. 3D power Doppler with glass body rendering shows
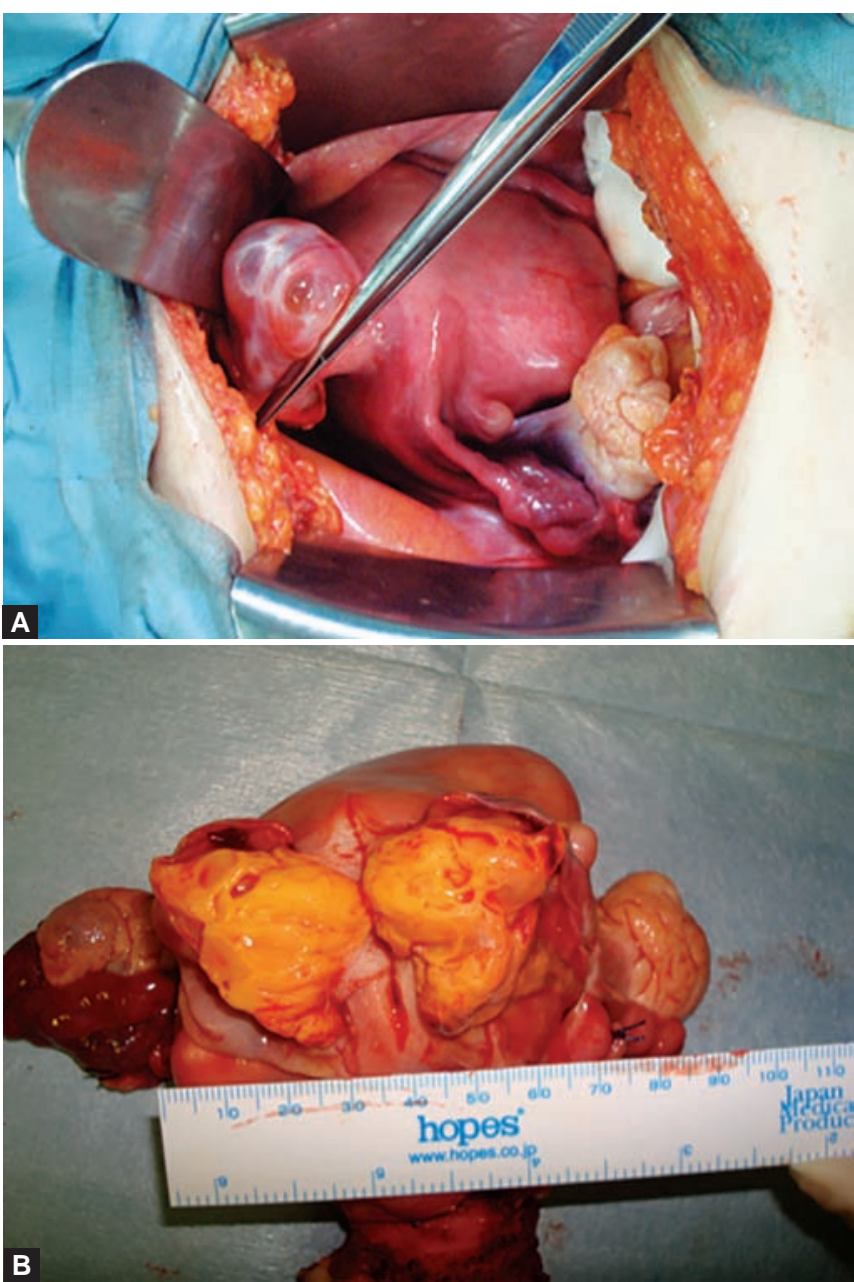

Figs 7A and B: Macroscopic specimen of a mesenchymal tumor: (A) during operation and (B) gross specimen

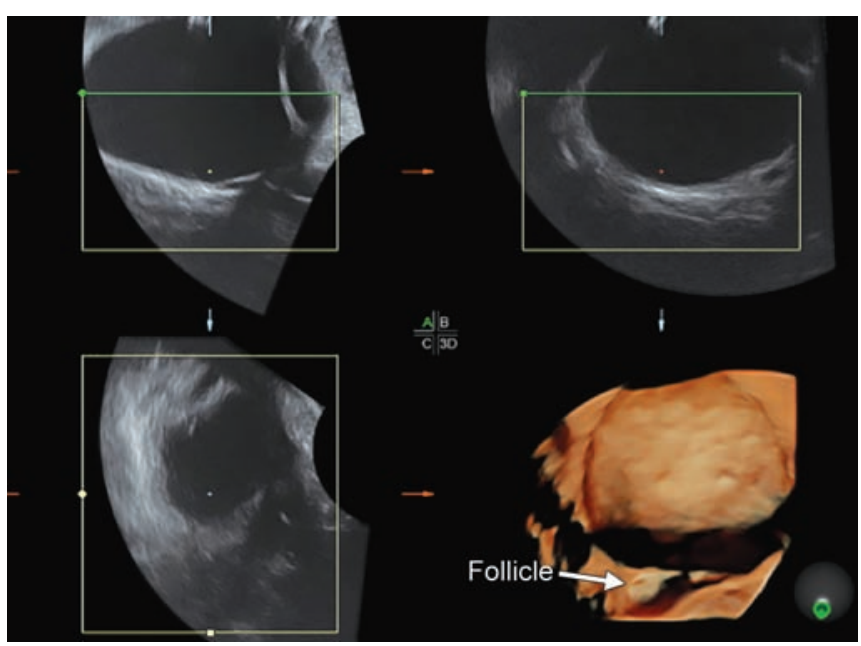

Fig. 8: Multiplanar view and HDlive images of a simple cyst diagnosed in a 42-year-old woman. A small follicular cyst is also depicted

a smooth vessel, no tortuosity, and no caliber change (Figs 13A and B). HDlive depicts the solid components, such as a hair ball (Figs $12 \mathrm{~A}$ and B), ${ }^{6}$ teeth, and even lipid substances (Figs 14A to C), which is very similar to the actual specimen (Figs 15A and B). 


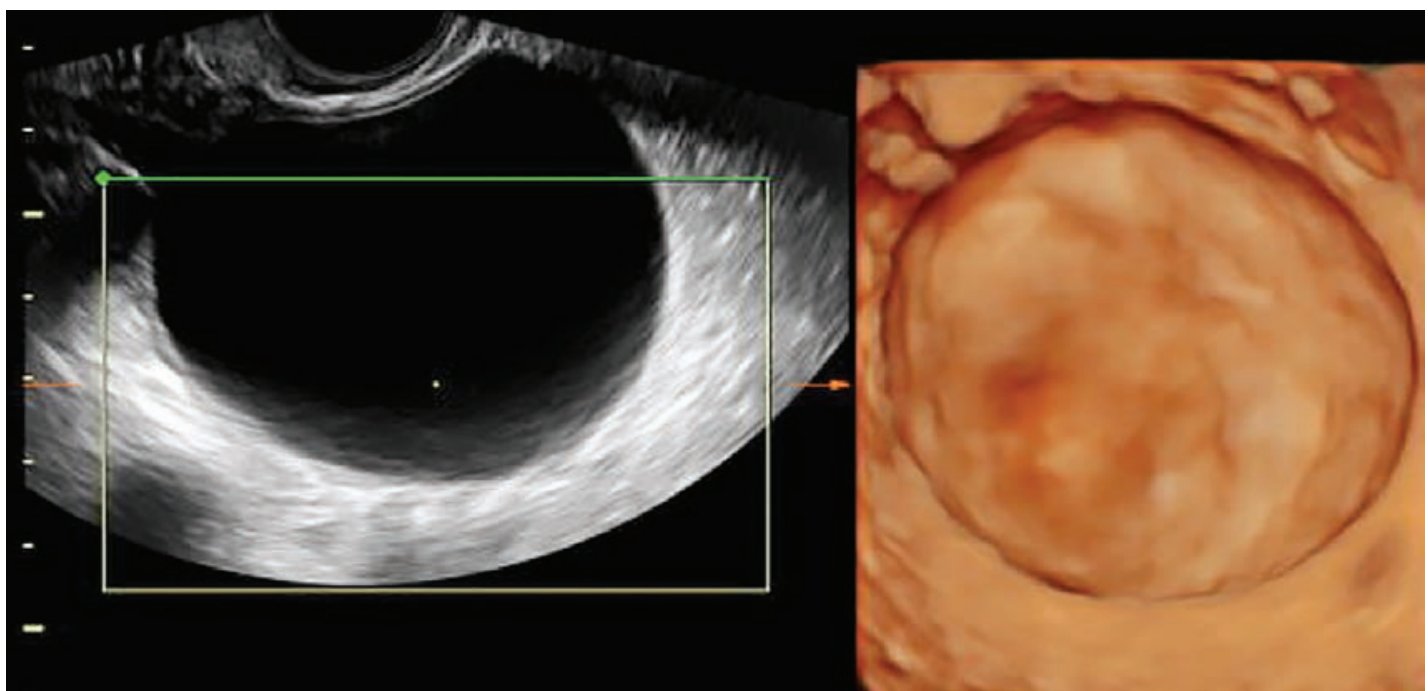

Fig. 9: Two-dimensional sonographic and HDlive images of a simple cyst diagnosed in a 38-year-old woman
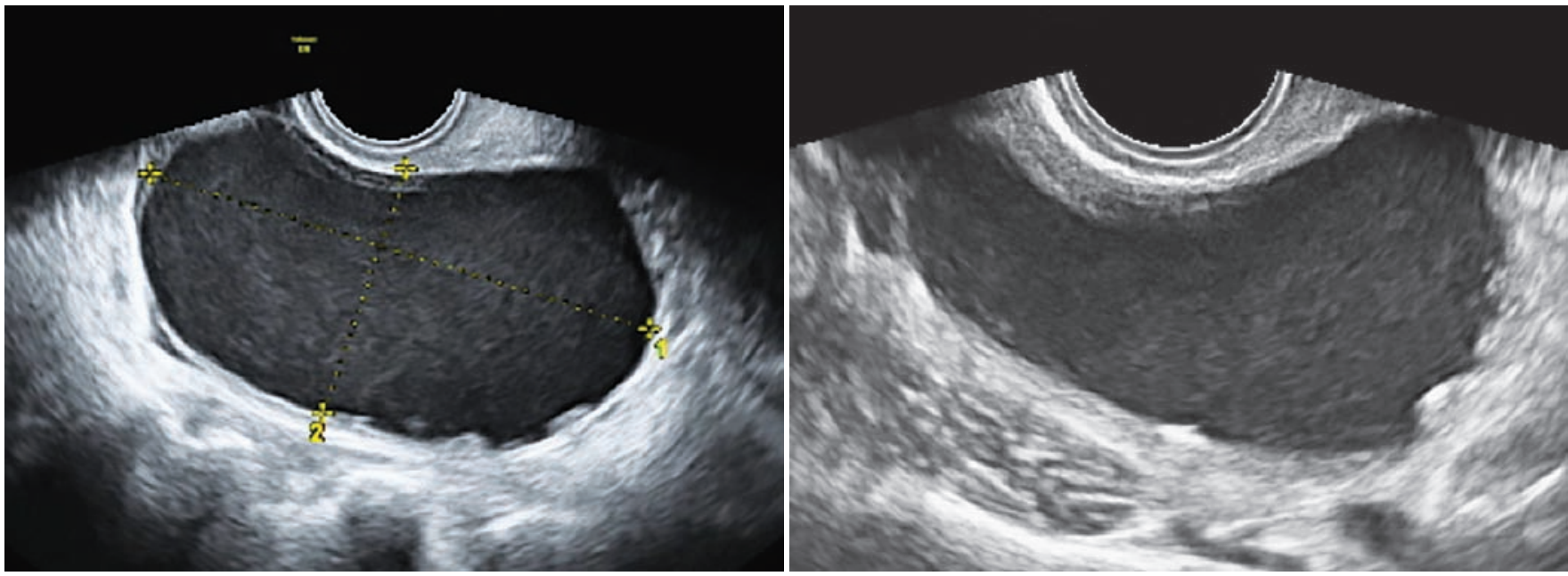

Fig. 10: Two-dimensional transvaginal sonographic images of a chocolate cyst (Courtesy: Reprinted with permission from Hata T et al) ${ }^{6}$

\section{Serous Cystadenofibroma}

Serous adenoma is a common benign ovarian tumor which may grow very large; therefore, it is called a giant ovarian cyst. 2D sonographic and HDlive features are similar to those of a simple cyst, with a thin wall and smooth surface (Figs 16A and B). The macroscopic specimen is a huge cyst containing only serous fluid (Fig. 17). Another type of serous tumor is a serous cystadenofibroma. It is a solid variant of benign serous tumors. The 2D sonographic image shows an anechoic cyst, with thin septations, and fine papillary projections (Fig. 18). ${ }^{6}$ HDlive clearly demonstrates smooth papillary projections, a smooth septum, and relatively smooth inner wall (Fig. 19). ${ }^{6}$ The solid part in the gross specimen can be effectively visualized with HDlive (Fig. 20). ${ }^{6}$

\section{Mucinous Cystadenofibroma}

Mucinous tumors are frequently multilocular, and a cystadenofibroma variant with solid components can
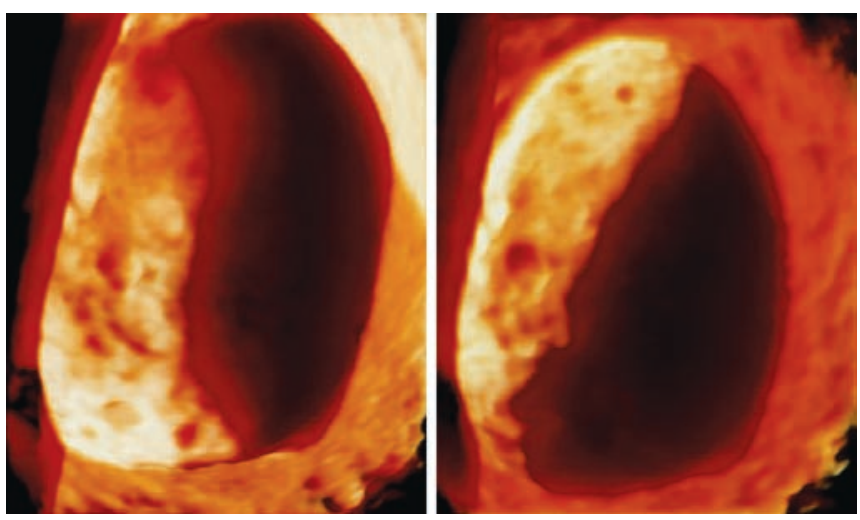

Fig. 11: HDlive images of a chocolate cyst with different directions of the light source (Courtesy: Reprinted with permission from HataT et al) ${ }^{6}$

be mistaken for a malignant tumor. The 2D sonographic image shows an anechoic and septate cyst (Fig. 21). Most of the tumors contain a fine echo which moves upon movement of the cyst because of the thick content. 2D 

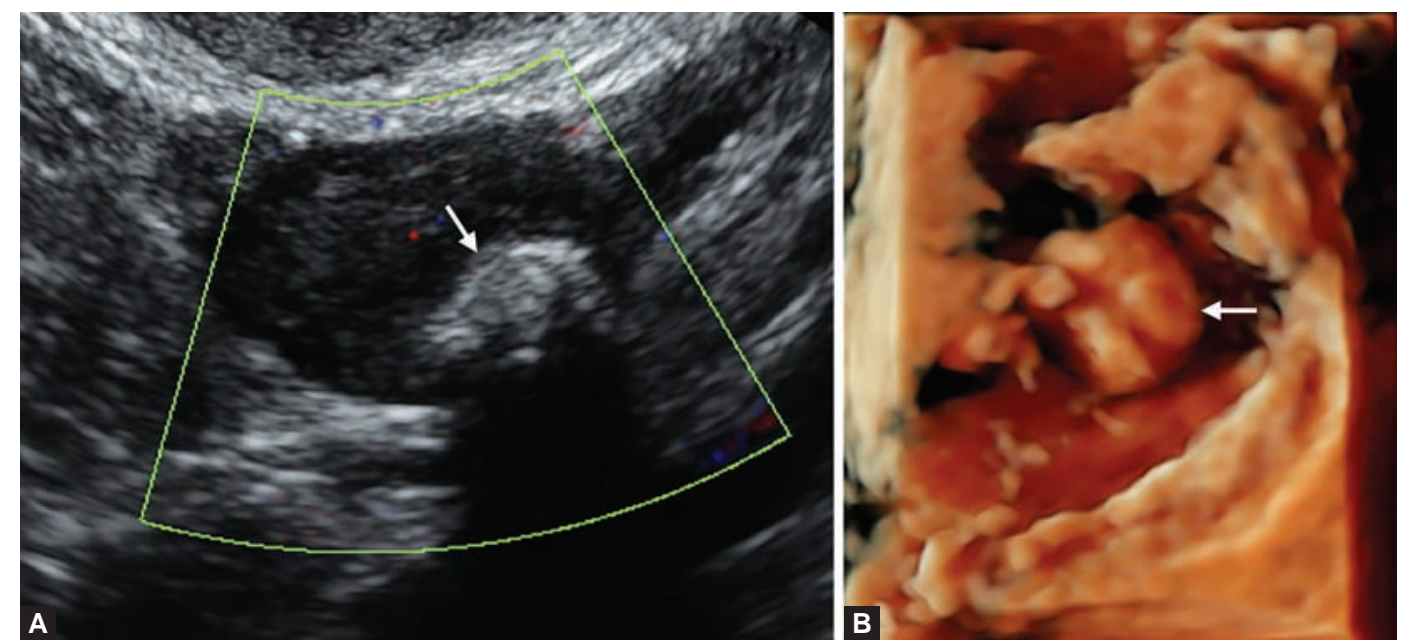

Figs 12A and B: Benign cystic teratoma in a 72-year-old woman: (A) Two-dimensional transvaginal sonographic image and (B) HDlive image. Arrows show a hair ball (Courtesy: Reprinted with permission from Hata T et al) ${ }^{6}$
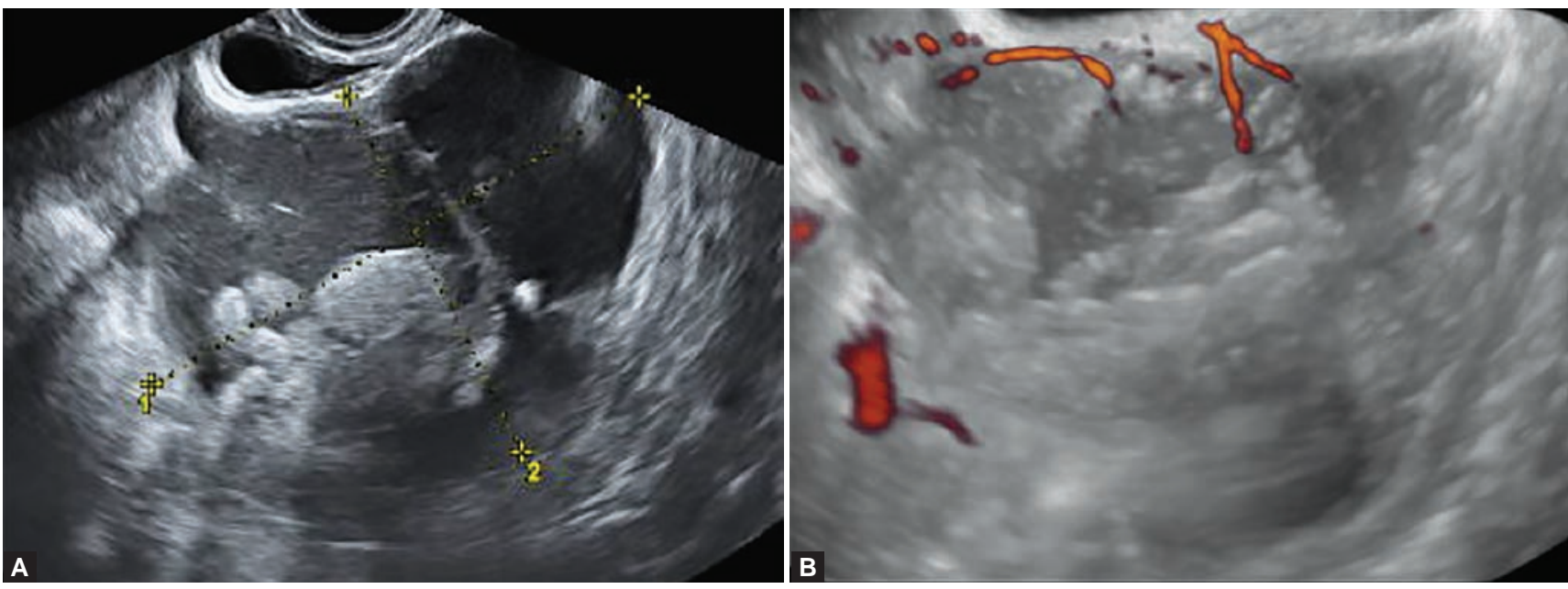

Figs 13A and B: Benign cystic teratoma in a 49-year-old woman: (A) Two-dimensional sonographic image and (B) three-dimensional power Doppler ultrasound image with glass body rendering
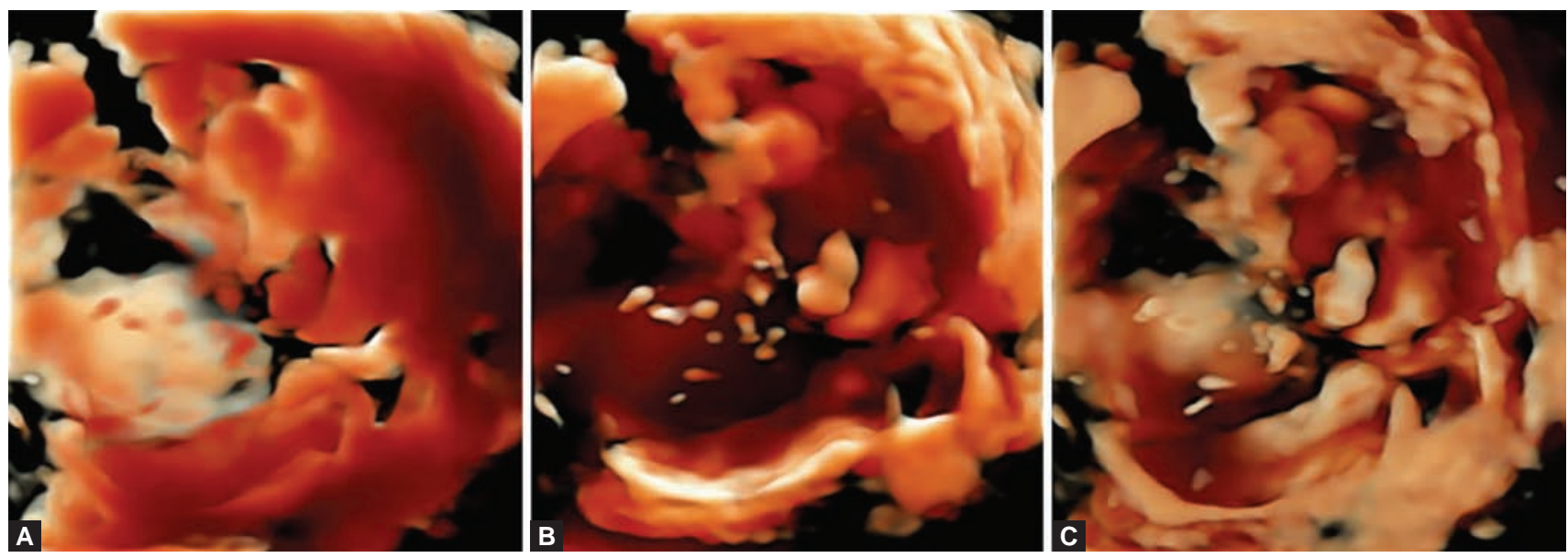

Figs 14A to C: HDlive images with different light sources of a benign cystic teratoma

color Doppler shows minimal vascularity (Fig. 22). 3D power Doppler demonstrates straight vessels and no caliber change (Fig. 23). HDlive clearly presents multiple solid nodules (Fig. 24), which are seen in a gross specimen (Fig. 25).

\section{Immature Teratoma}

Immature teratoma is a rare malignant germ cell tumor. In 2D sonography, hyperechoic or solid components are predominant compared to cystic lesions (Fig. 26). 


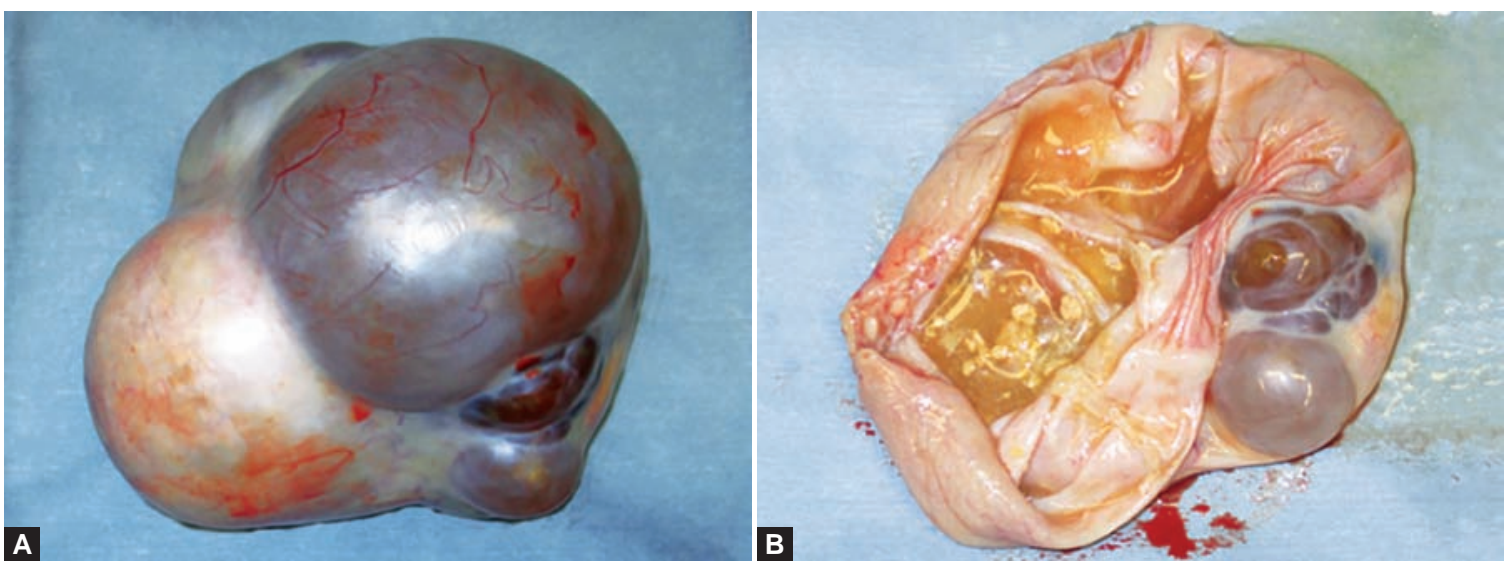

Figs 15A and B: Macroscopic specimen of a benign cystic teratoma:

(A) The intact tumor and (B) The dissected tumor
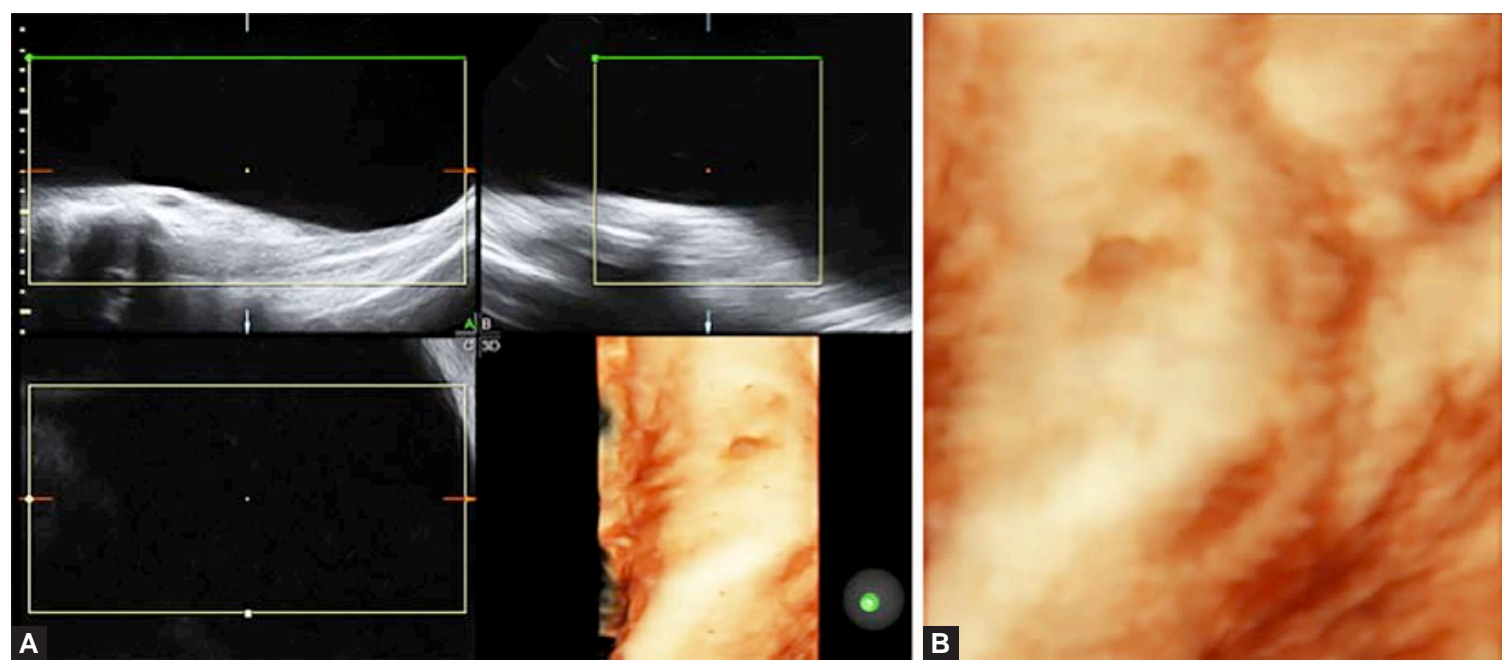

Figs 16A and B: Multiplanar view and HDlive images of a serous adenoma (A) and (B) HDlive image

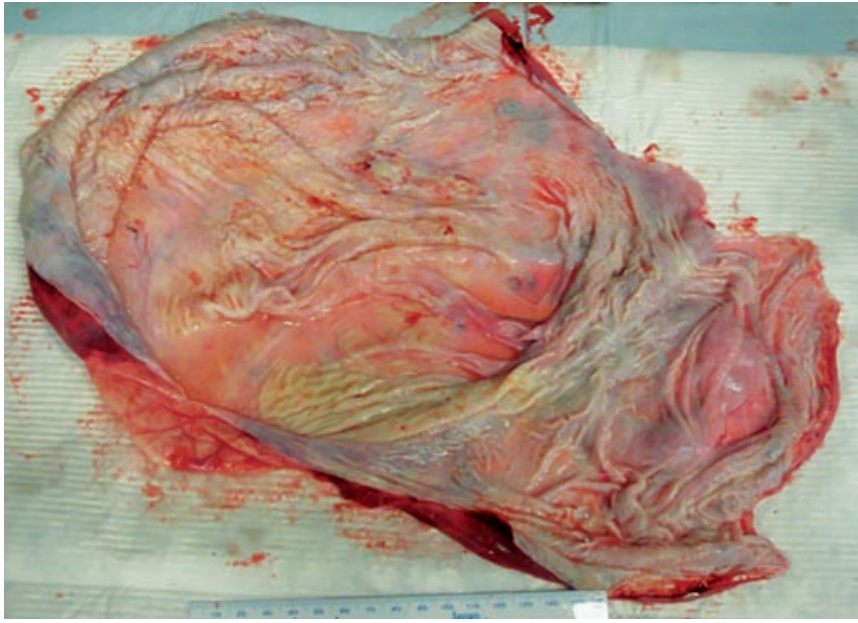

Fig. 17: Macroscopic specimen of a serous adenoma

3D power Doppler depicts vessels, which are branching and show caliber changes (Fig. 27A), and 3D HD-flow also reveals a dense vascularity (Fig. 27B). On HDlive, solid components are evident, showing irregular papillary projections with a thick septate cyst (Fig. 28). Features in HDlive can be seen in actual specimens (Figs 29A and B).

\section{Serous Adenocarcinoma}

Here, we evaluate two cases of ovarian cancer at different stages. In one case with serous adenocarcinoma stage Ia, 2D sonography shows a cystic lesion with irregular papillary projections (Fig. 30A). ${ }^{6}$ With 2 D HD-flow, a welldefined vascular network is circulating at the periphery of the solid component (Fig. 30B). 3D color Doppler depicts a very dense vascularity within the solid component (Fig. 31). HDlive clearly shows the thickened septum, and irregular papillary projections (Fig. 32) similar to the gross specimen (Fig. 33). ${ }^{6}$ Serous adenocarcinoma stage Ic also shows hyperechoic nodules (Fig. 34). 2D HD-flow and 2D power Doppler demonstrate increased vascularity within the nodules (Figs 35A and B). 3D power Doppler demonstrates numerous vessels with branching, irregular caliber changes and tortuosity (Fig. 36). HDlive clearly depicts thick, irregular septum, and papillary projections, and the cavity is mostly occupied with the solid components (Fig. 37), which can also be identified in the gross specimen (Figs 38A and B). 

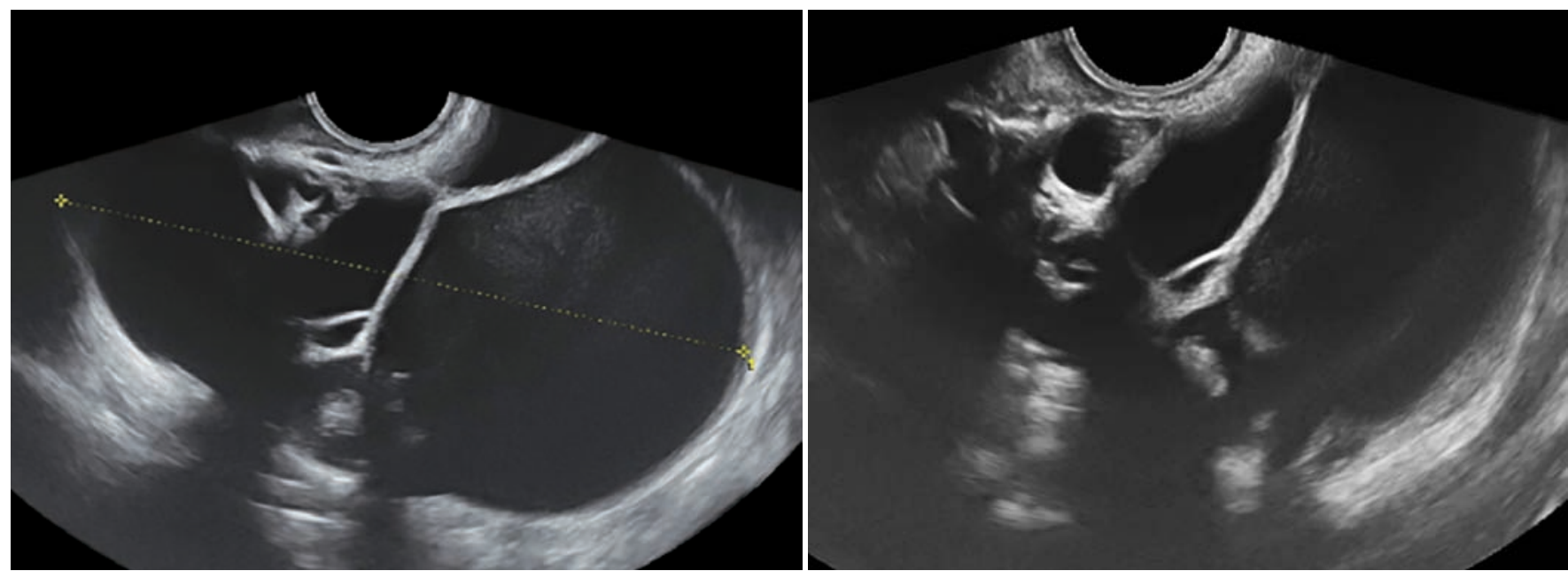

Fig. 18: Two-dimensional transvaginal sonographic images of a serous cystadenofibroma (Courtesy: Reprinted with permission from Hata T et al) ${ }^{6}$

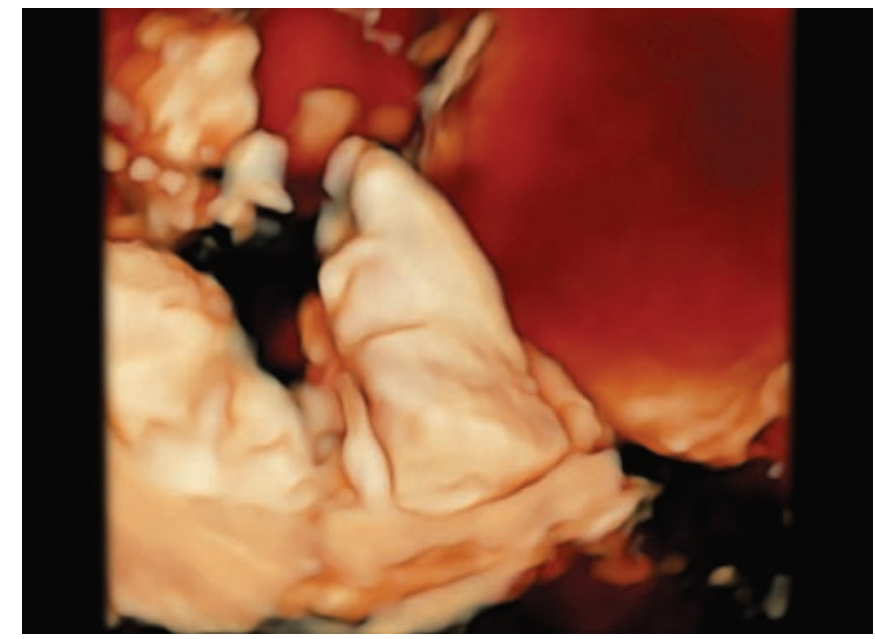

Fig. 19: HDlive image of a serous cystadenofibroma (Courtesy: Reprinted with permission from Hata T et al) ${ }^{6}$
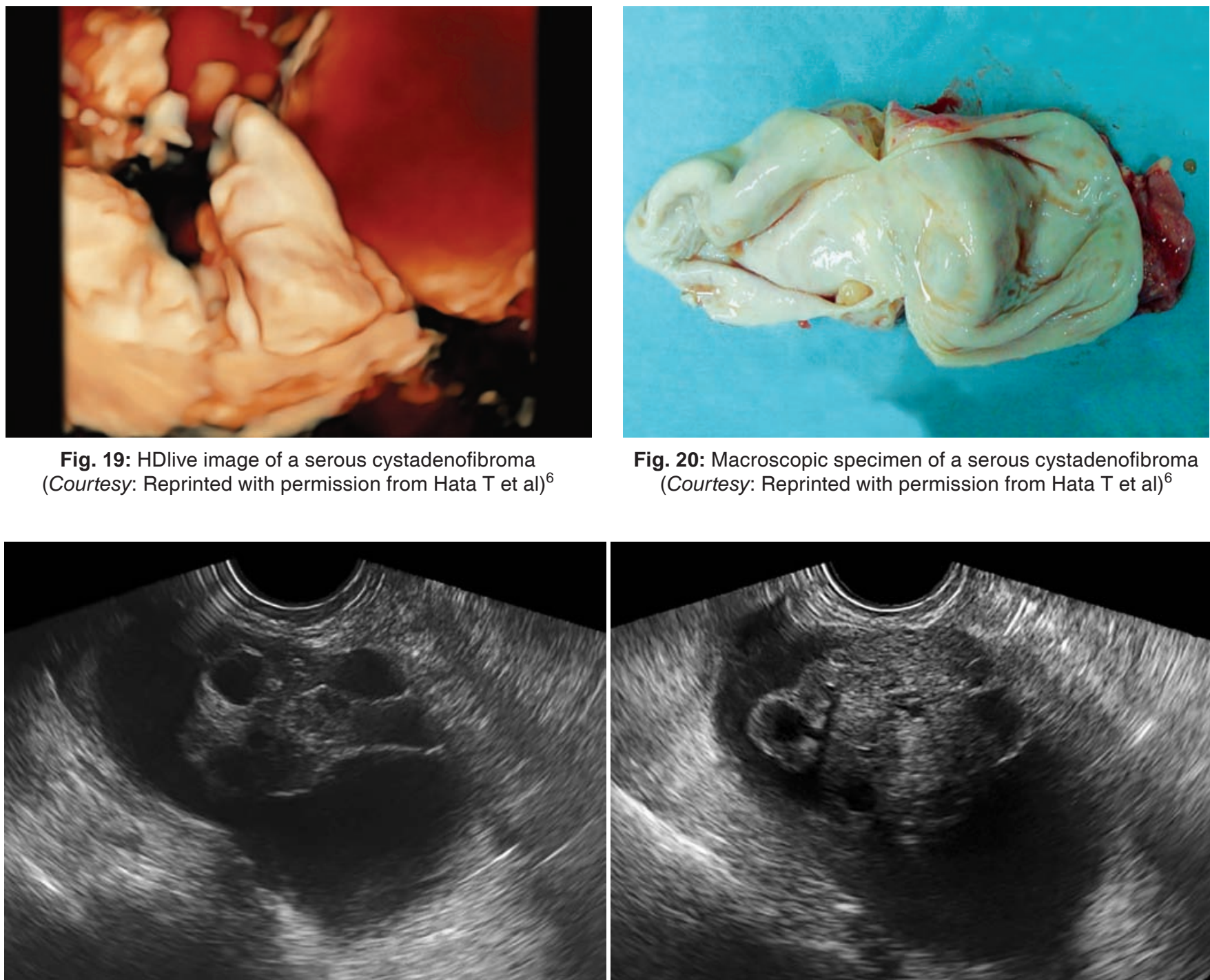

Fig. 20: Macroscopic specimen of a serous cystadenofibroma (Courtesy: Reprinted with permission from Hata T et al) ${ }^{6}$

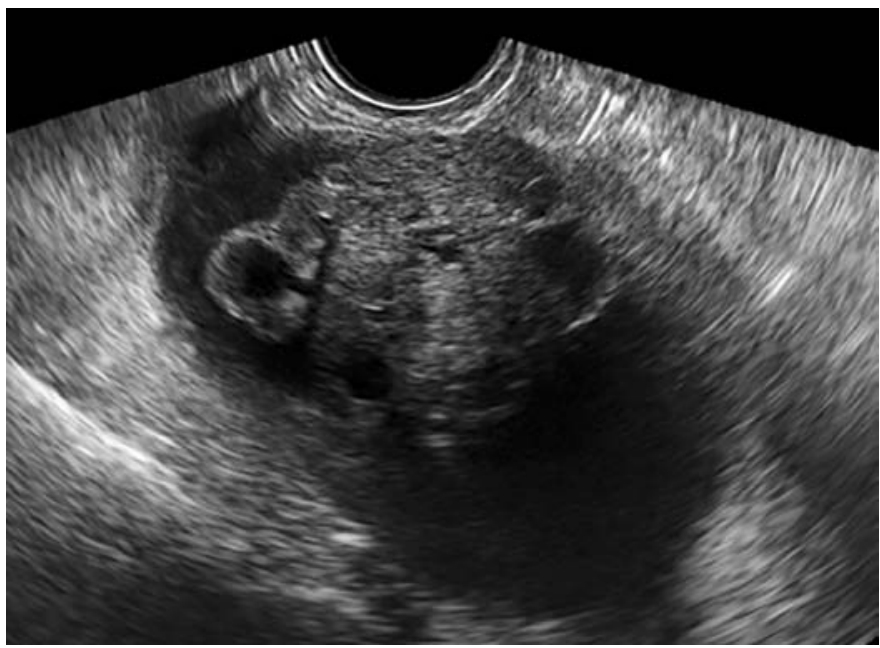

Fig. 21: Two-dimensional transvaginal sonographic images of a mucinous cystadenofibroma

\section{Mucinous Cystadenocarcinoma}

Two cases of mucinous cystadenocarcinoma stage Ic are evaluated. 2D sonography shows a multiloculated

structure, with irregular papillary projections, and an indistinct border (Figs 39A and 43A and B). 2D color Doppler reveals increased vascularity (Figs 39B and 


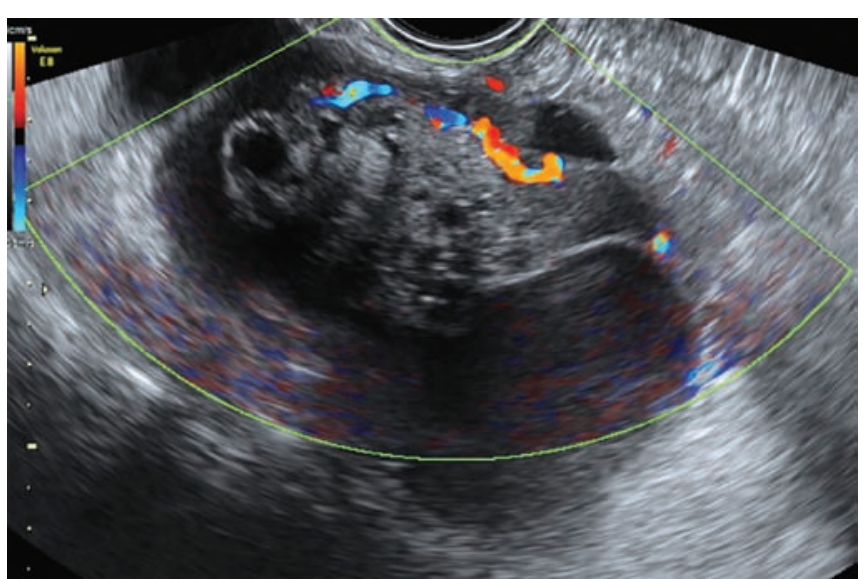

Fig. 22: Two-dimensional color Doppler ultrasound image of a mucinous cystadenofibroma

44). 3D power Doppler presents branching of vessels and changes in caliber (Fig. 40). Employing HDlive, solid components are well delineated with numerous papillary projections (Figs 41, 45 and 46), similar to the gross specimens (Figs 42 and 47).

\section{Mixed Epithelial Tumor (Malignant)}

This is a rare tumor, also known as carcinosarcoma. ${ }^{19} \mathrm{~A}$ huge mass, thick wall, thickened septum, and huge solid components can be seen in 2D sonographic images of a malignant mixed epithelial tumor (Fig. 48A). ${ }^{6}$ D color Doppler shows its vascularity supplying the entire mass,
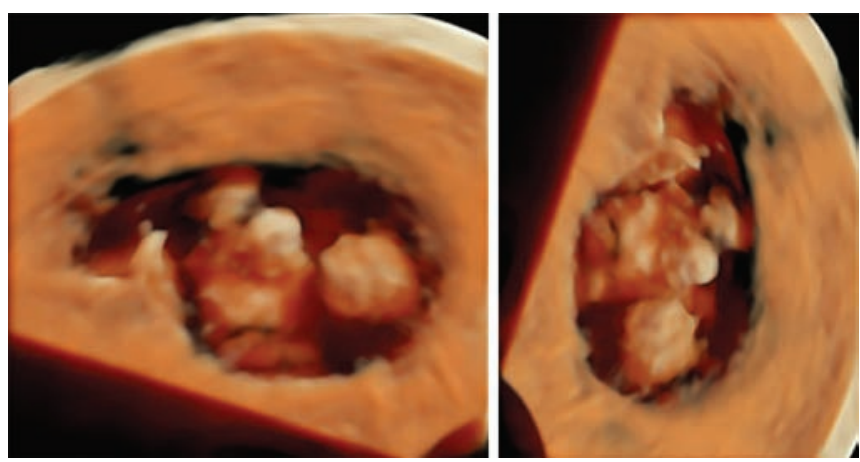

Fig. 24: HDlive images of a mucinous cystadenofibroma
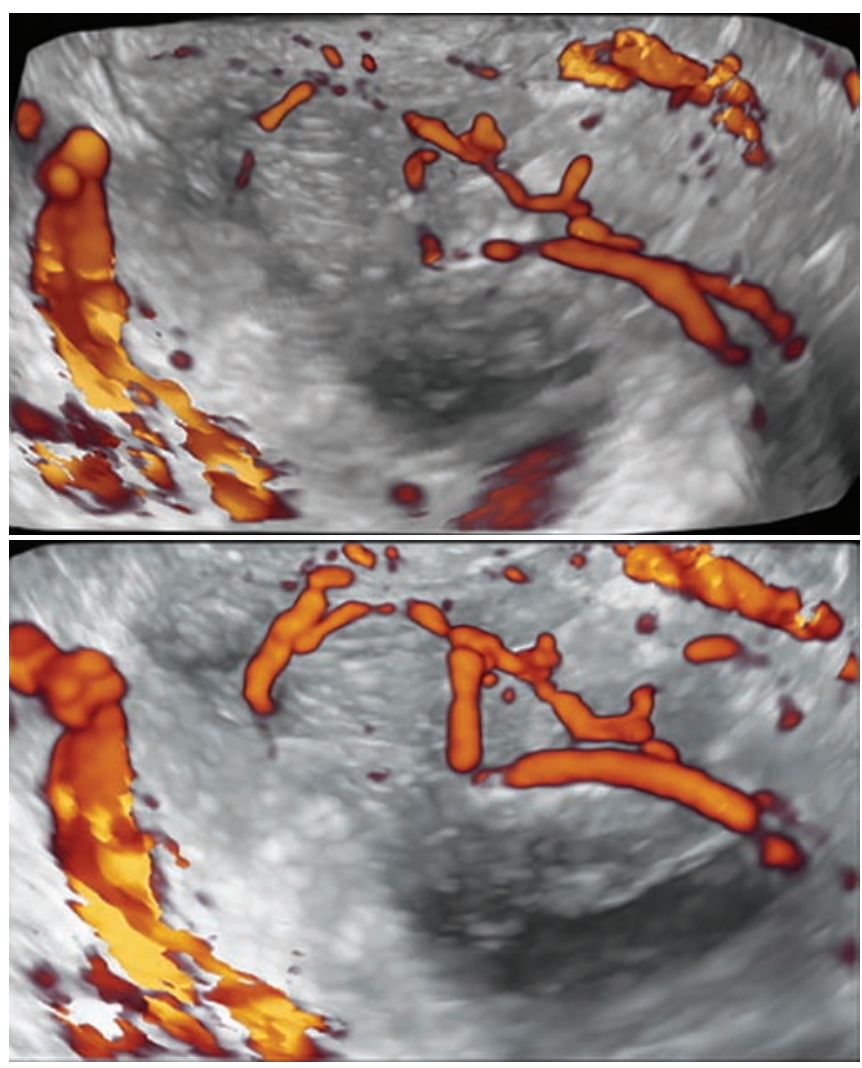

Fig. 23: Three-dimensional power Doppler ultrasound images of a mucinous cystadenofibroma

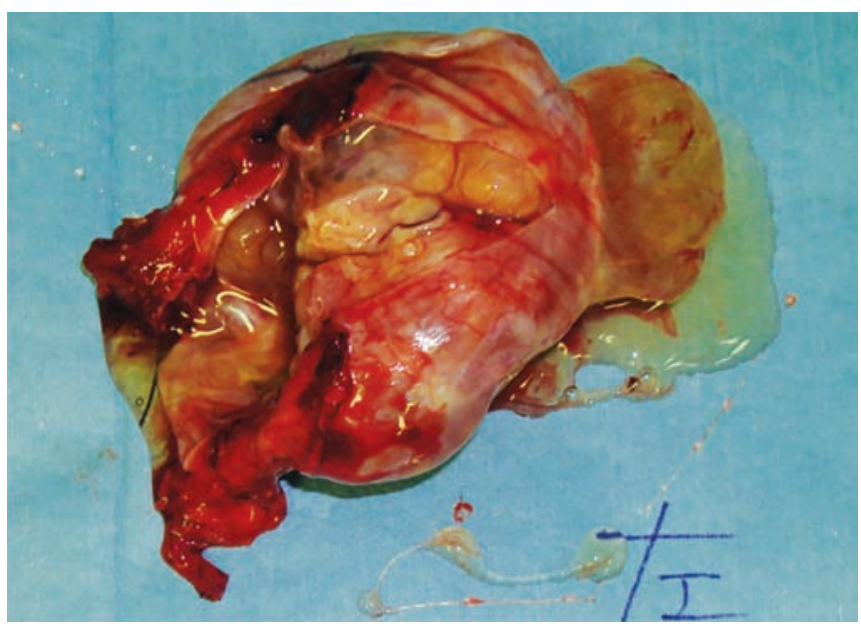

Fig. 25: Macroscopic specimen of a mucinous cystadenofibroma
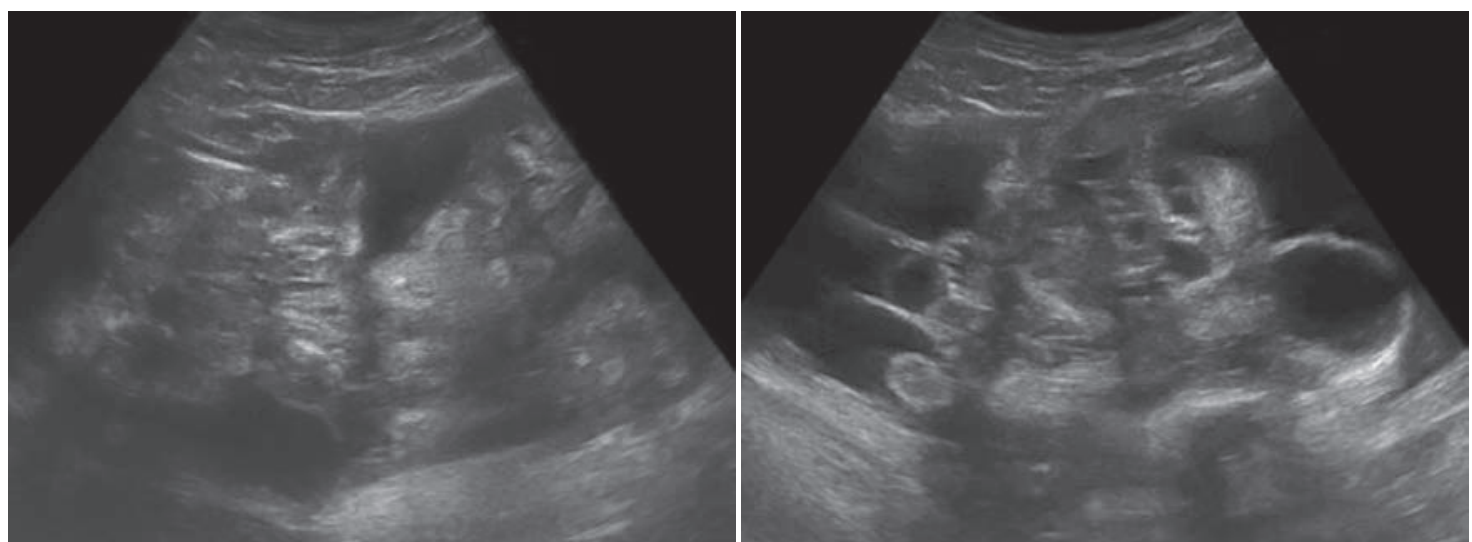

Fig. 26: Two-dimensional sonographic images of a borderline immature teratoma (G1) 

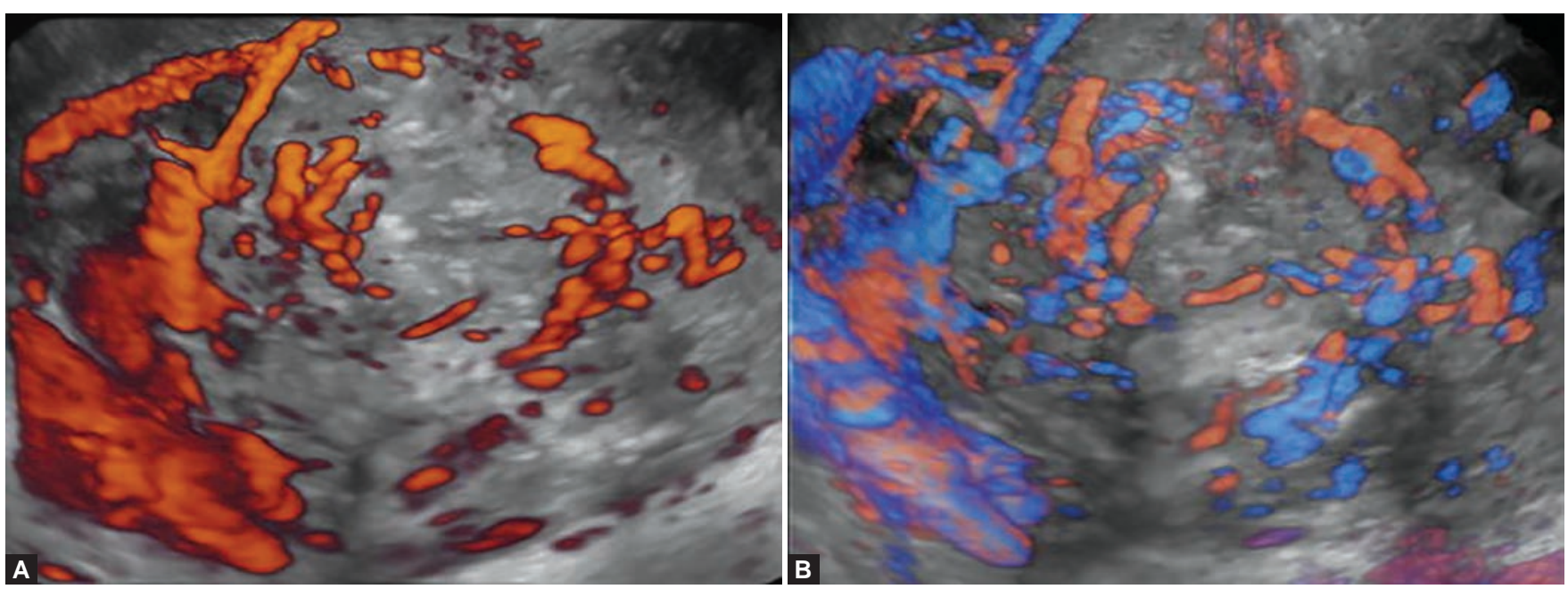

Figs 27A and B: Three-dimensional (3D) power Doppler (A) and 3D HD-flow images (B) of an immature teratoma
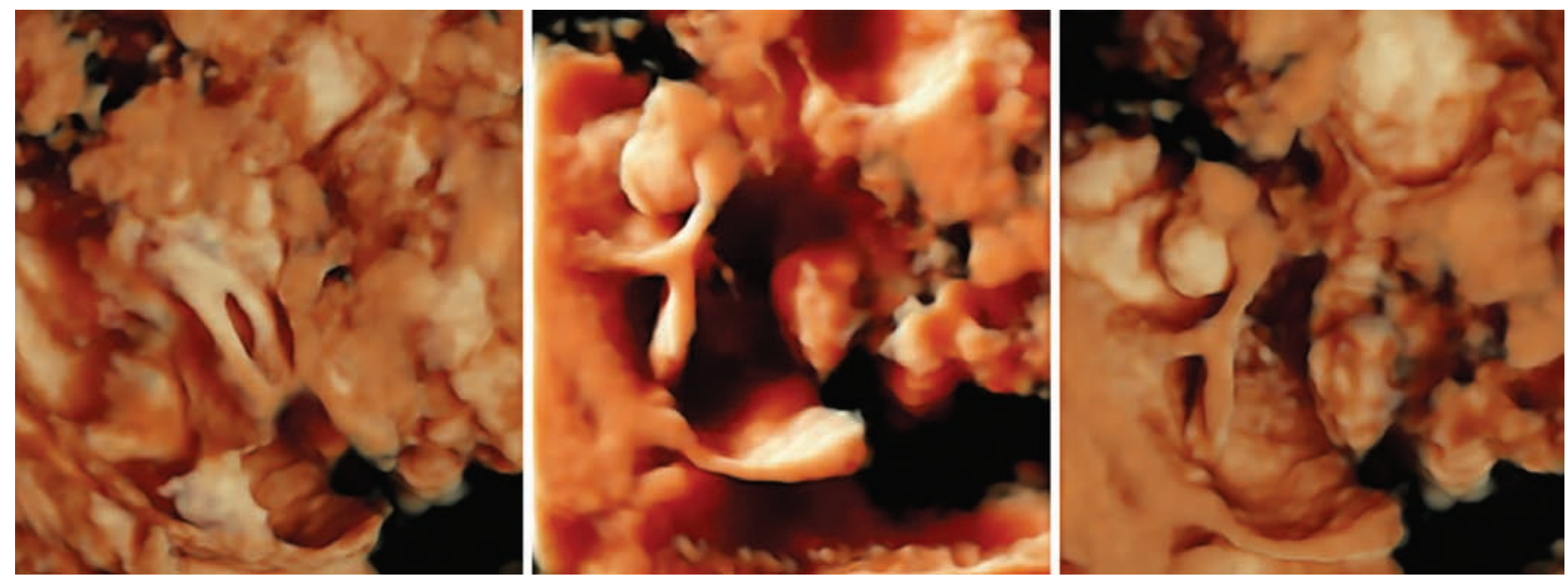

Fig. 28: HDlive images of an immature teratoma
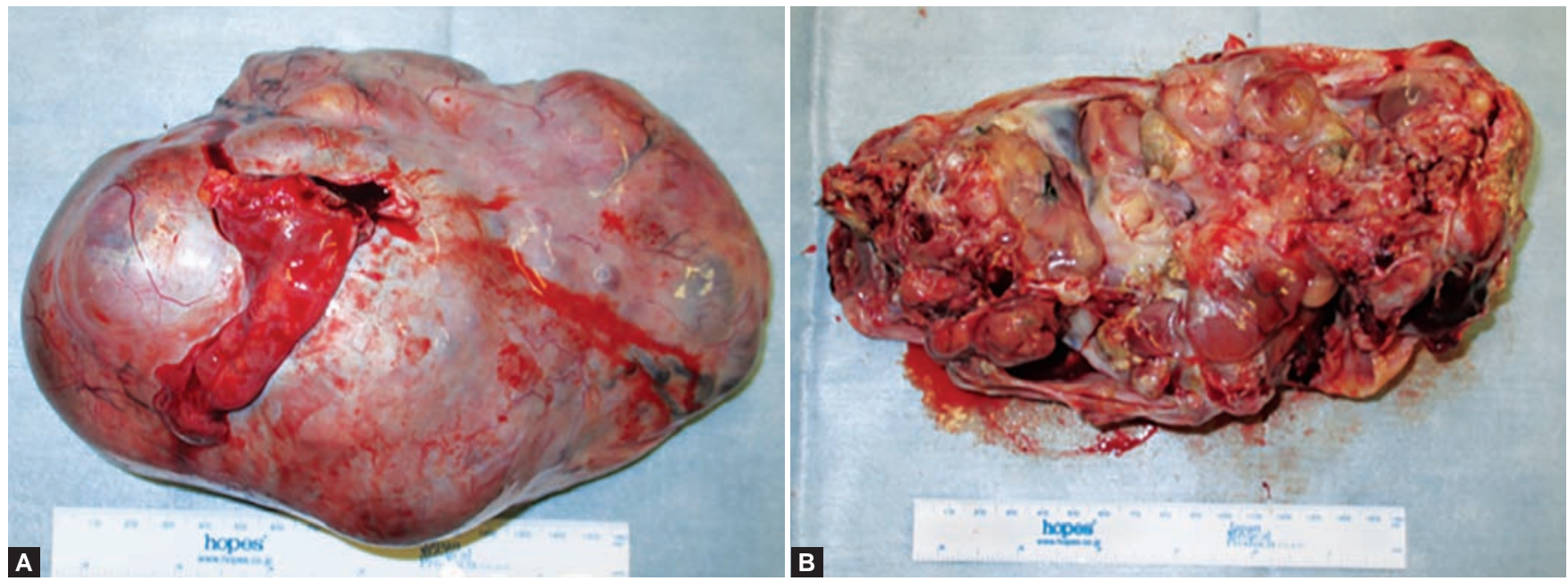

Figs 29A and B: Macroscopic specimen of an immature teratoma:

(A) The intact tumor and (B) the dissected tumor 


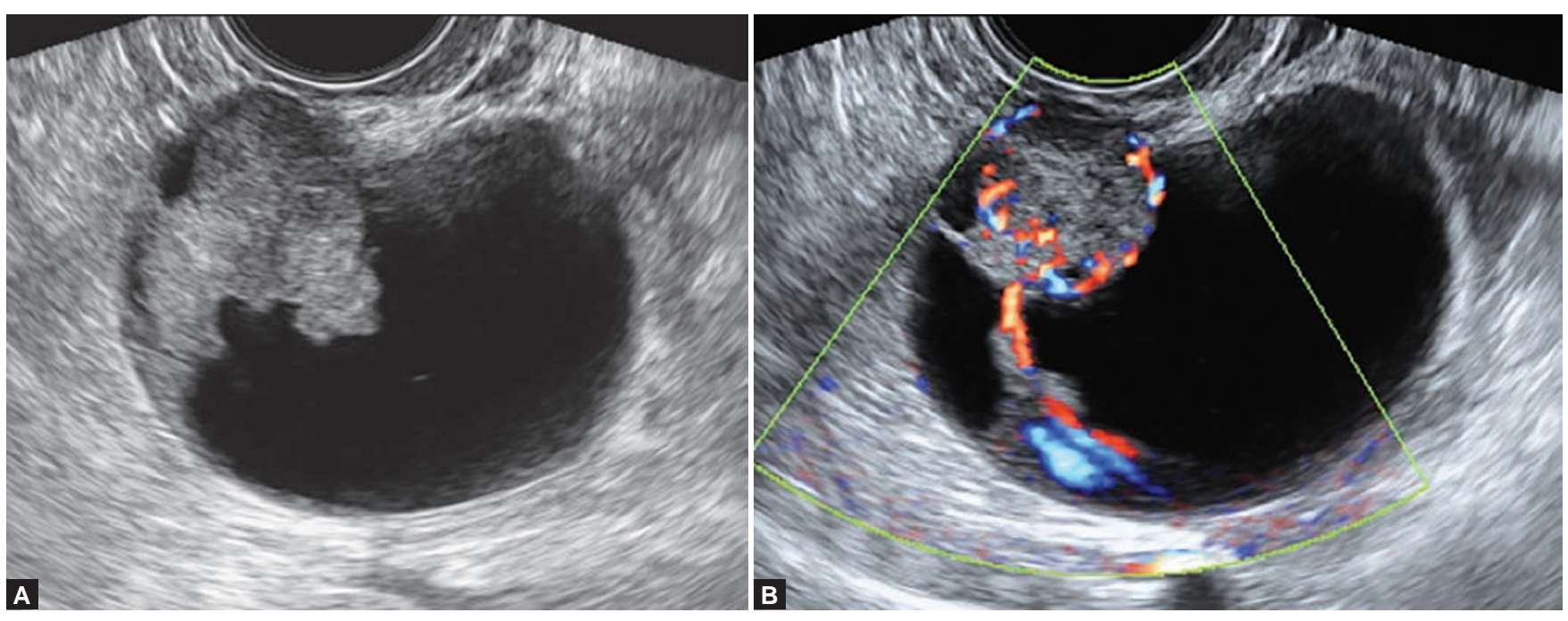

Figs 30A and B: Two-dimensional sonographic (A) and HD-flow images (B) of a serous adenocarcinoma stage la (Courtesy: Reprinted with permission from Hata T et al) ${ }^{6}$
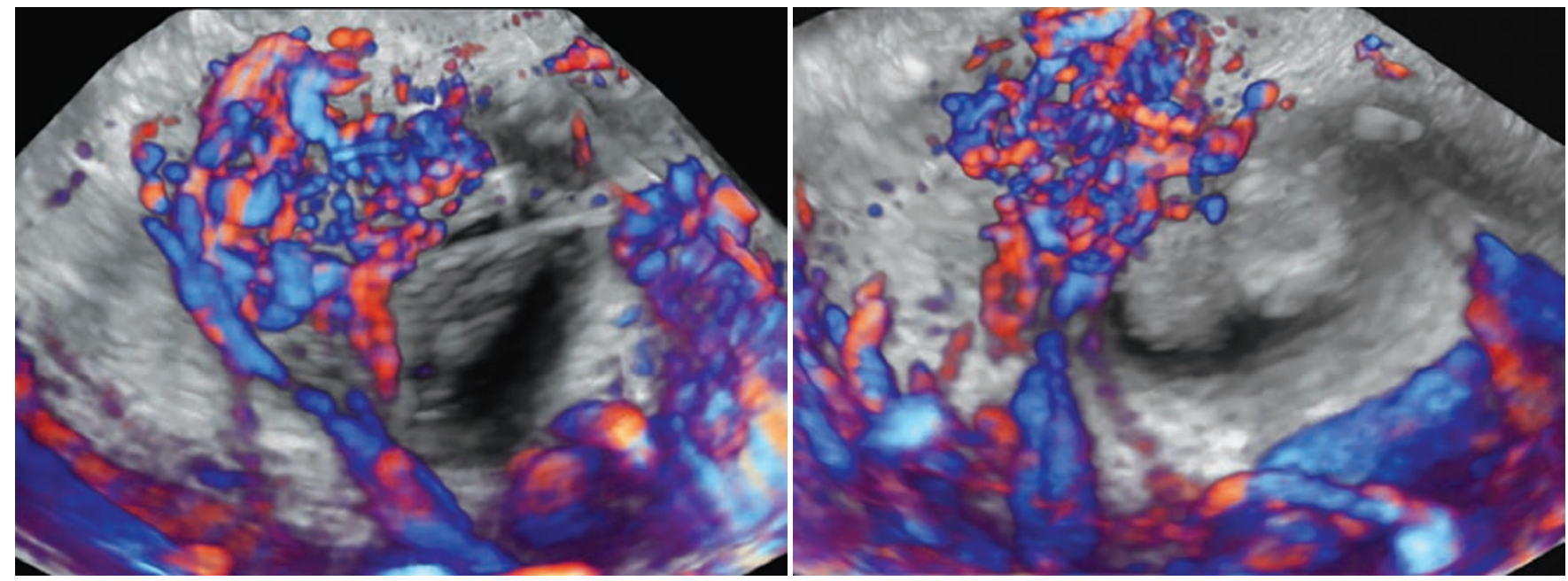

Fig. 31: Three-dimensional color Doppler ultrasound images of a serous adenocarcinoma stage la
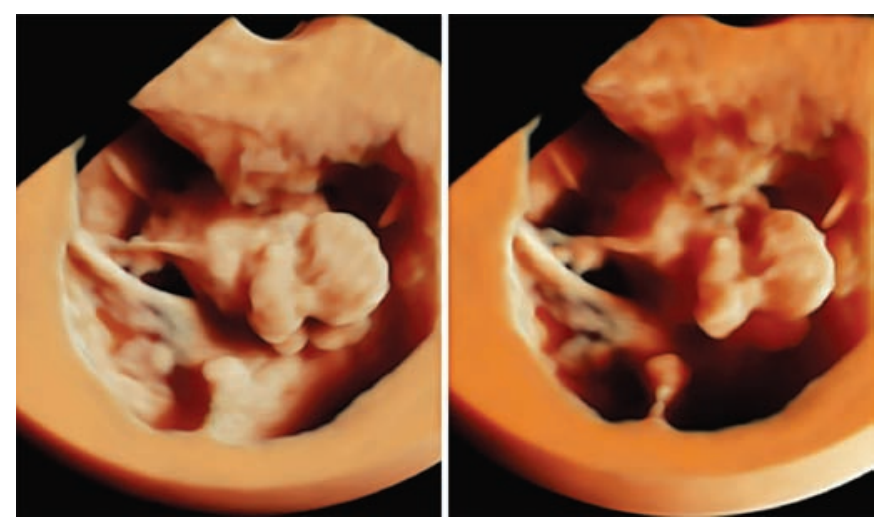

Fig. 32: HDlive images of a serous adenocarcinoma stage la (Courtesy: Reprinted with permission from Hata T et al) ${ }^{6}$

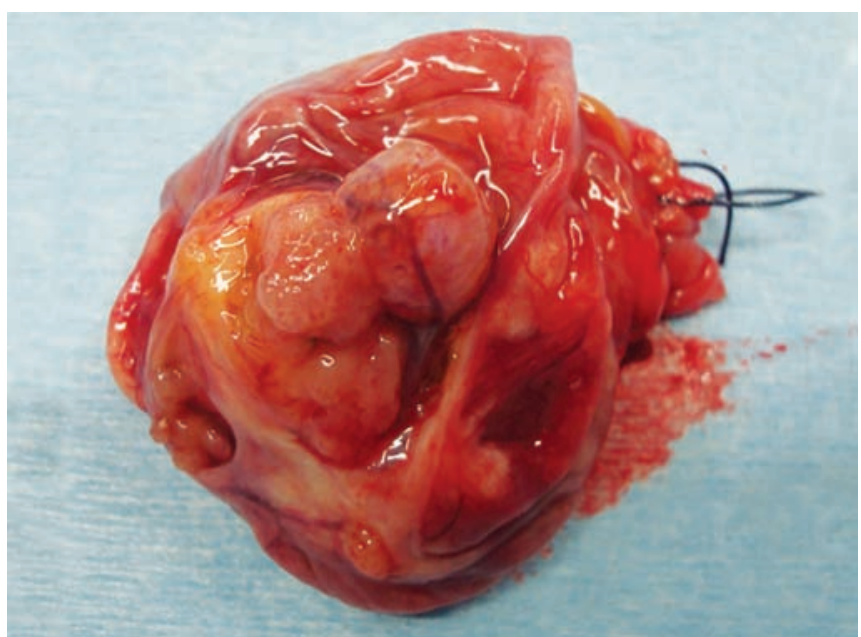

Fig. 33: Macroscopic specimen of a serous adenocarcinoma stage la (Courtesy: Reprinted with permission from Hata T et al) ${ }^{6}$ 


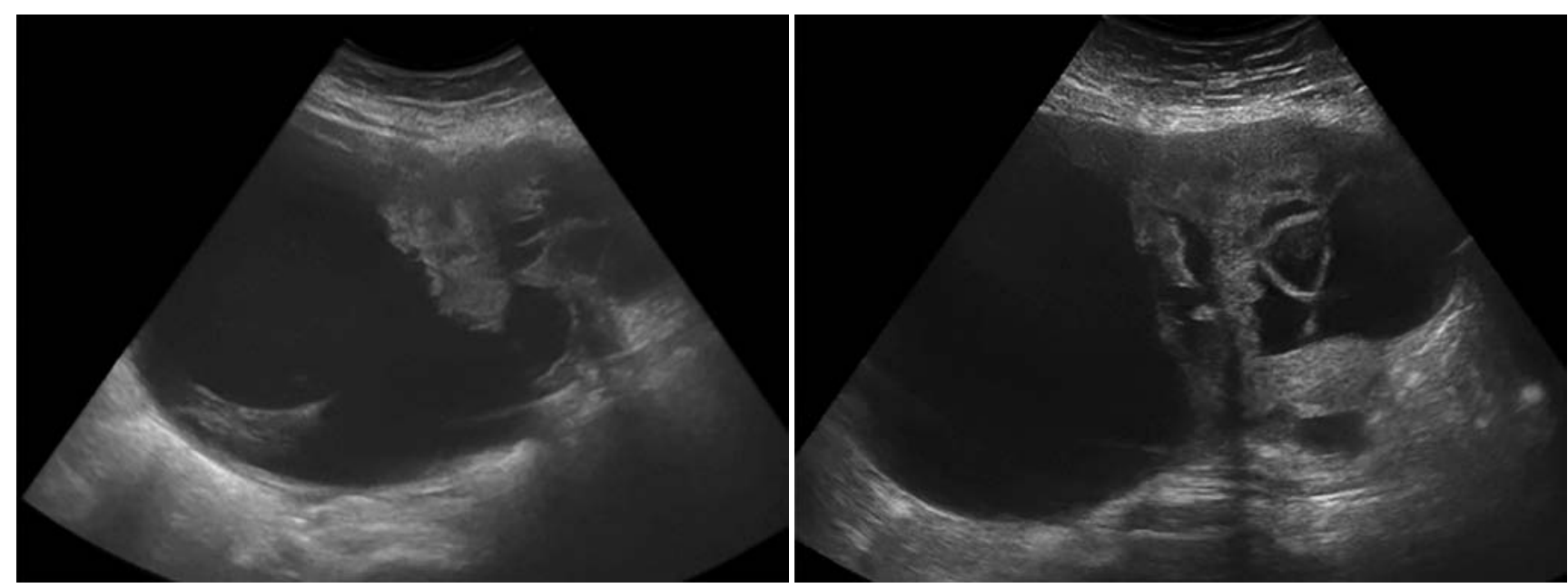

Fig. 34: Two-dimensional transabdominal sonographic images of a serous adenocarcinoma stage Ic
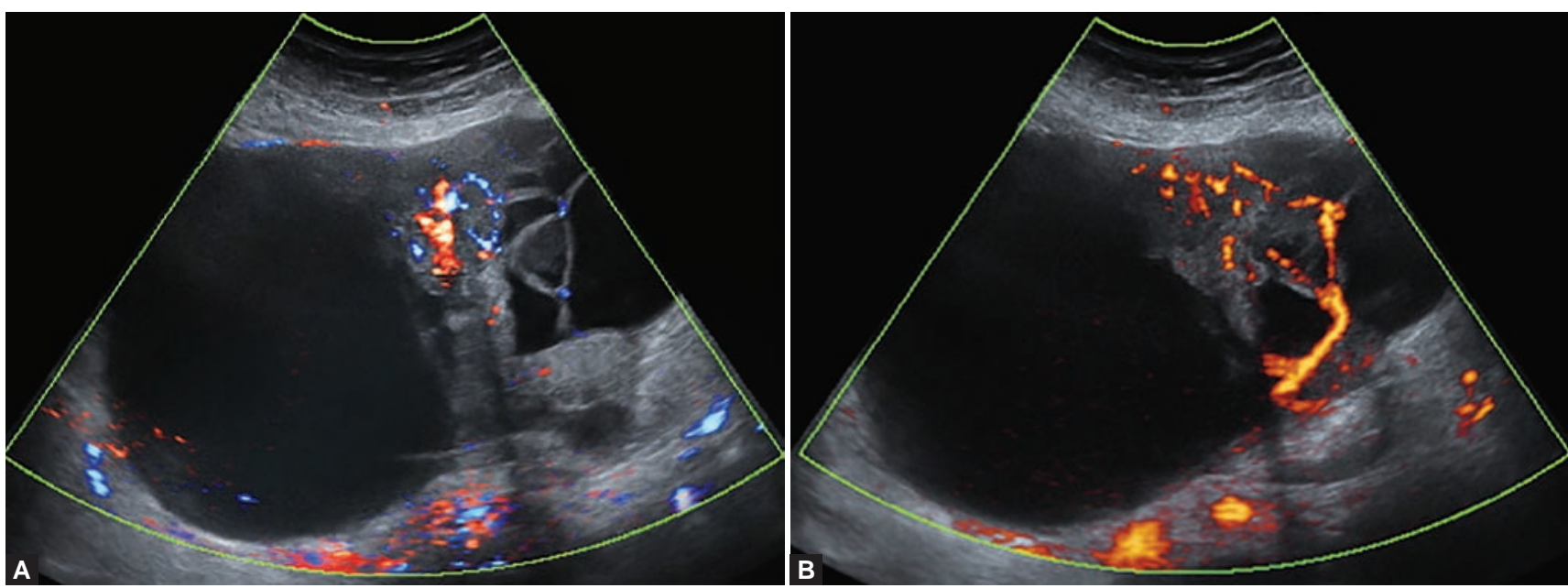

Figs 35A and B: Serous adenocarcinoma stage Ic: (A) two-dimensional HD-flow image and (B) two-dimensional power Doppler ultrasound image

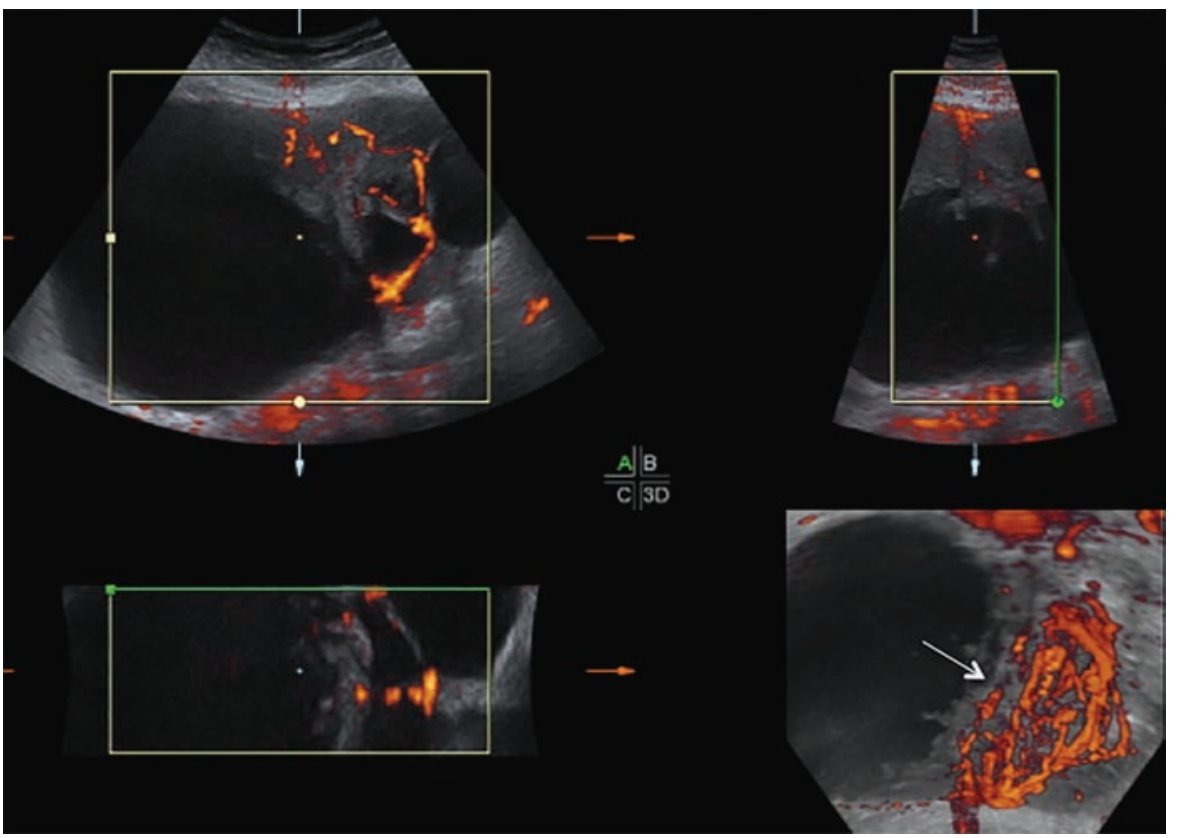

Fig. 36: Multiplanar view and three-dimensional power Doppler ultrasound image of a serous adenocarcinoma stage Ic. Arrow shows numerous vessels with branching, irregular caliber changes and tortuosity 

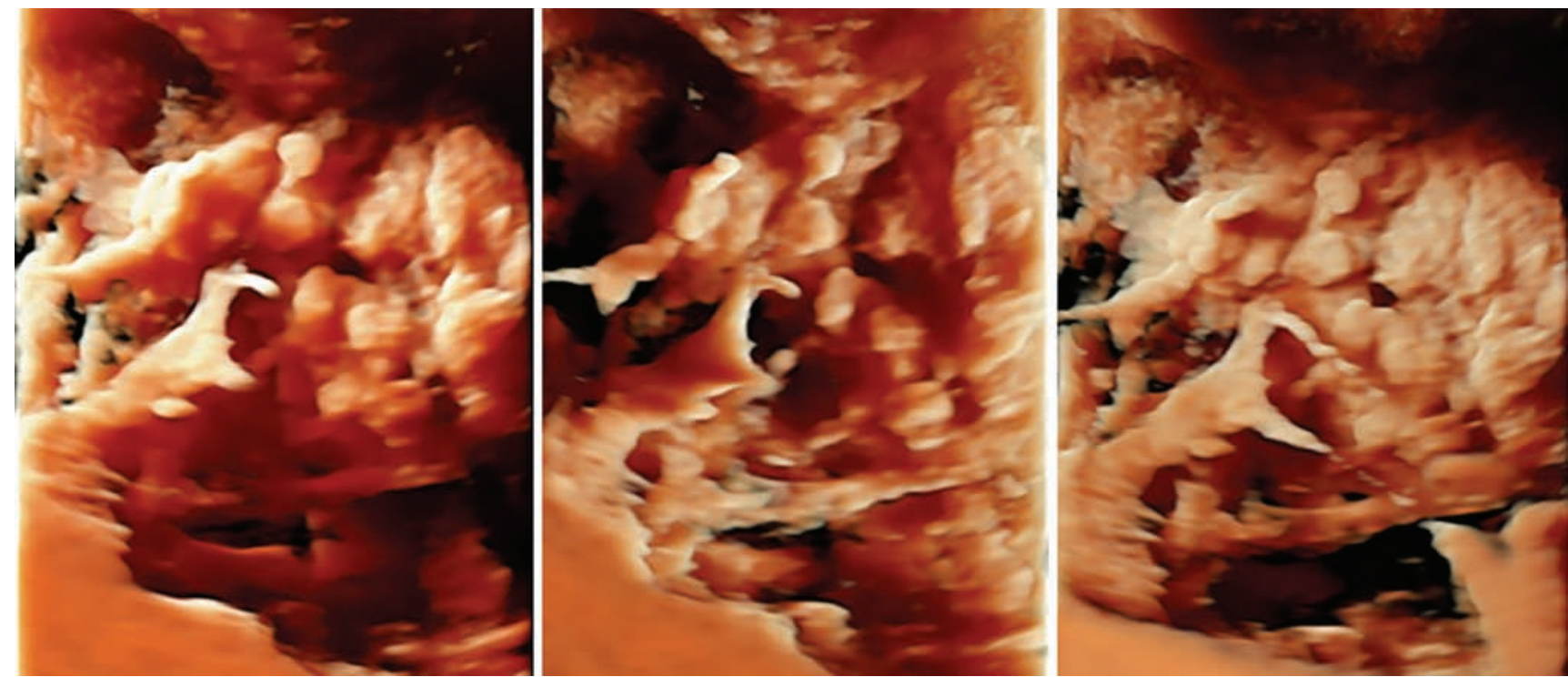

Fig. 37: HDlive images with different light sources of a serous adenocarcinoma stage Ic
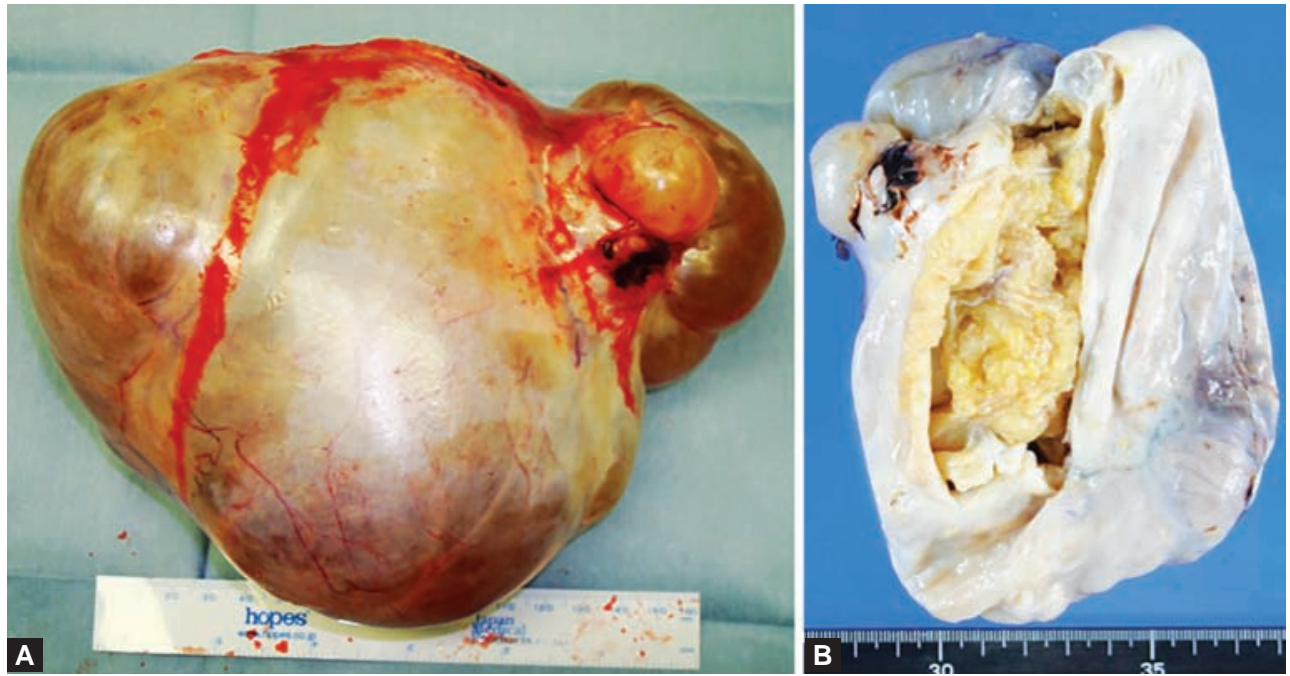

Figs 38A and B: Macroscopic specimen of a serous adenocarcinoma stage Ic:

(A) The intact tumor and (B) the dissected tumor
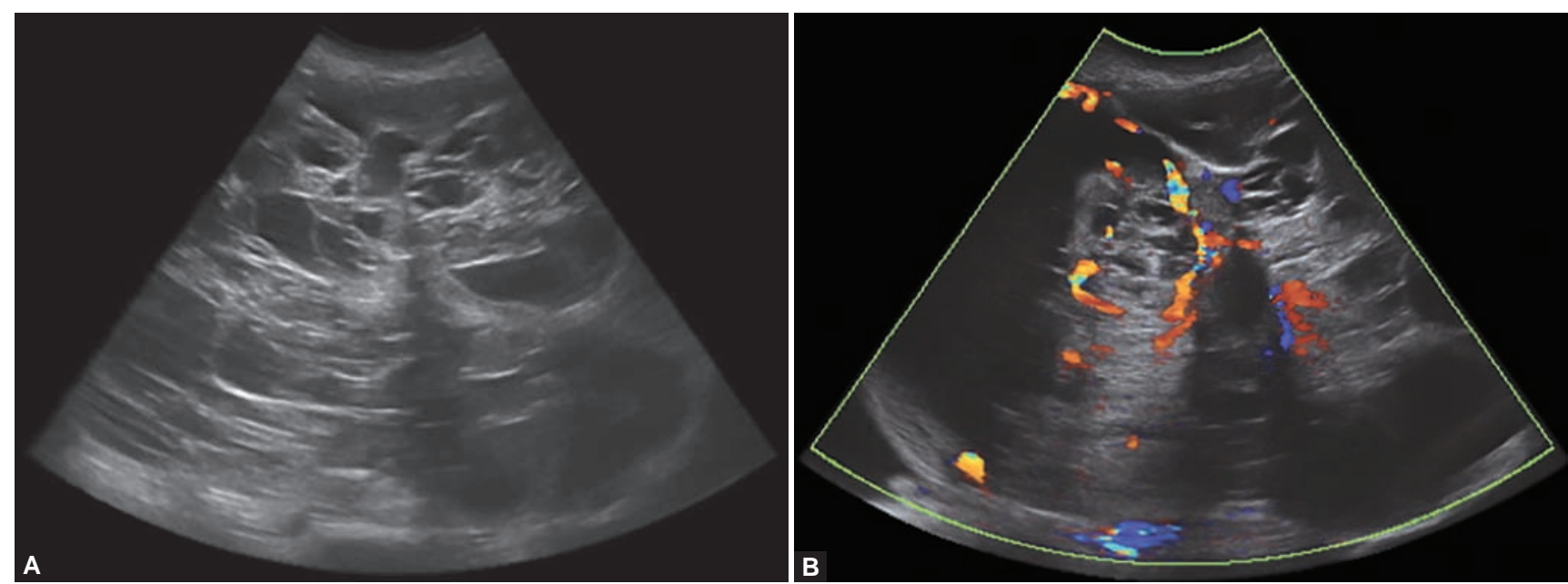

Figs 39A and B: Two-dimensional transabdominal sonographic (A) and color Doppler ultrasound images (B) of a mucinous cystadenocarcinoma stage Ic in a 45-year-old woman 


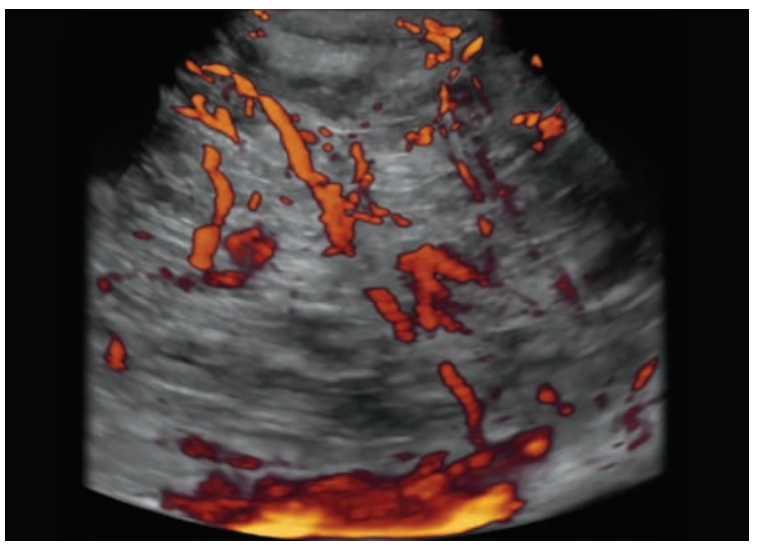

Fig. 40: Three-dimensional power Doppler ultrasound image of a mucinous cystadenocarcinoma stage Ic in a 45-year-old woman including the solid components (Fig. 48B). HDlive clearly reveals the thickened septum and irregular surface of solid components (Fig. 49). ${ }^{6}$ The gross specimen is similar to the features seen on HDlive (Fig. 50). ${ }^{6}$

\section{FALLOPIAN TUBE}

Usually, the fallopian tube is not visible in 2D sonographic images. The presence of an underlying disease might cause distention of the lumen or thickening of the walls, making sonographic features remarkable. It may also be mistaken as a cystic lesion of the ovary, and so warrants further evaluation.
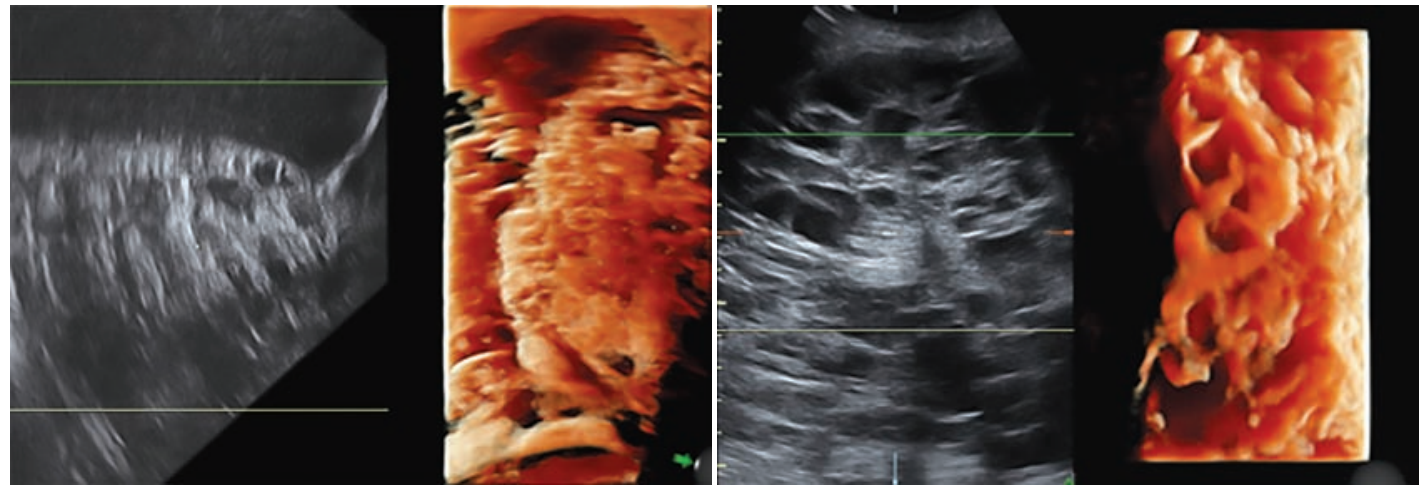

Fig. 41: HDlive images of a mucinous cystadenocarcinoma stage Ic in a 45-year-old woman

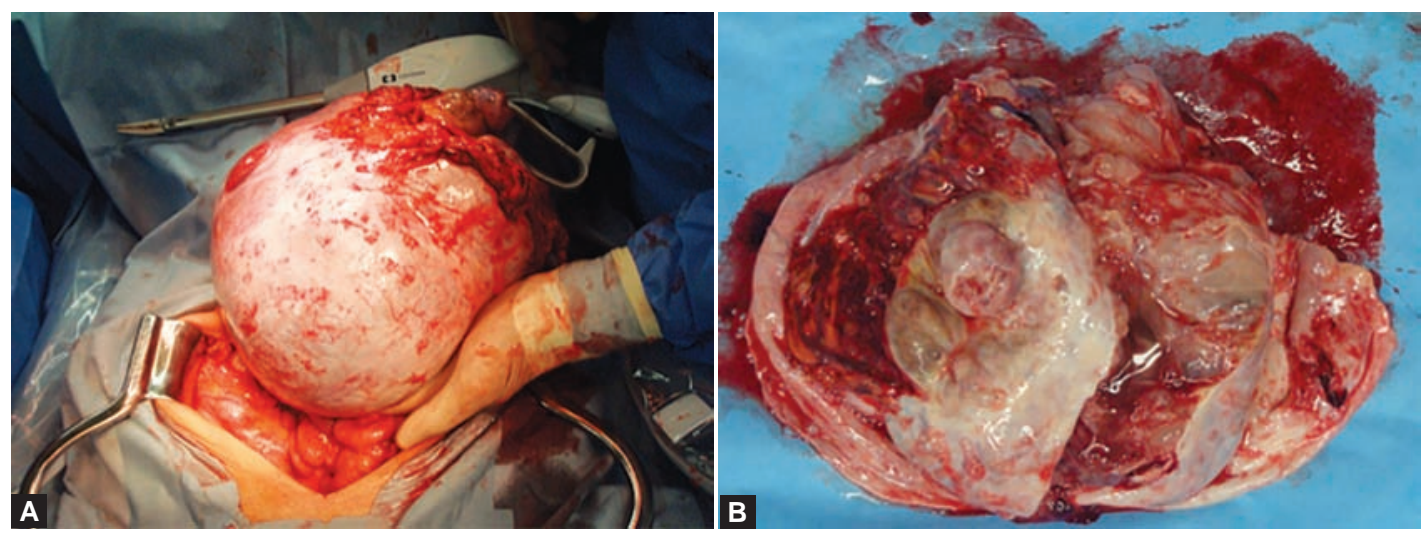

Figs 42A and B: Macroscopic specimen of a mucinous cystadenocarcinoma stage lc in a 45-year-old woman: (A) picture of the intact tumor and (B) picture of the dissected tumor
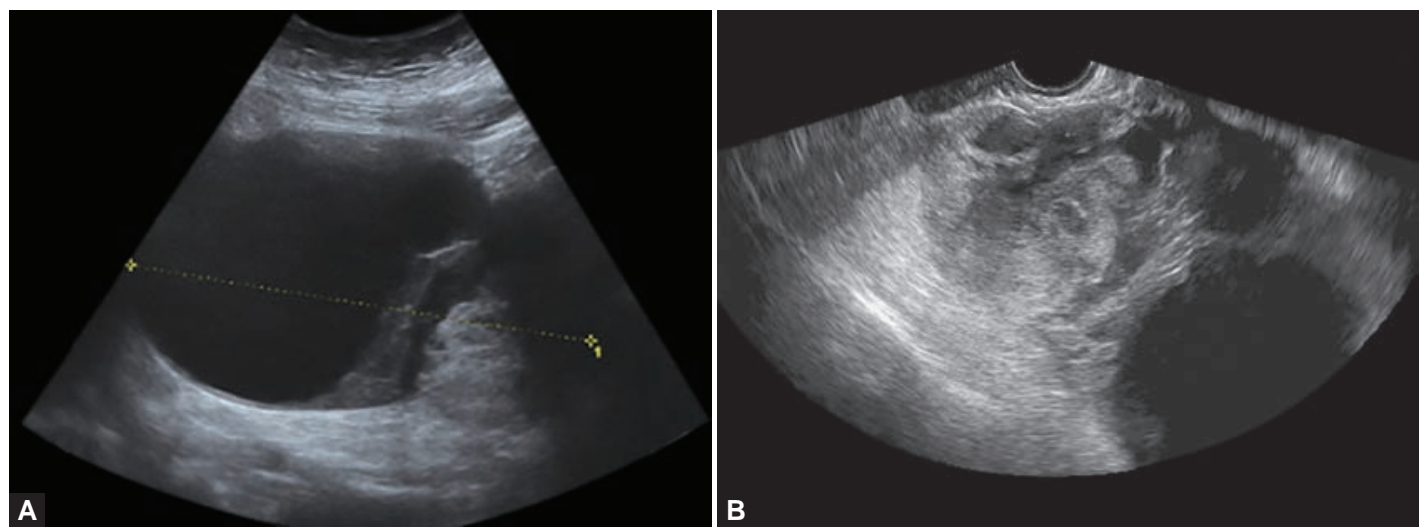

Figs 43A and B: Two-dimensional sonographic images of a mucinous cystadenocarcinoma stage lc in a 47-year-old woman: (A) Transabdominal image and (B) transvaginal image 


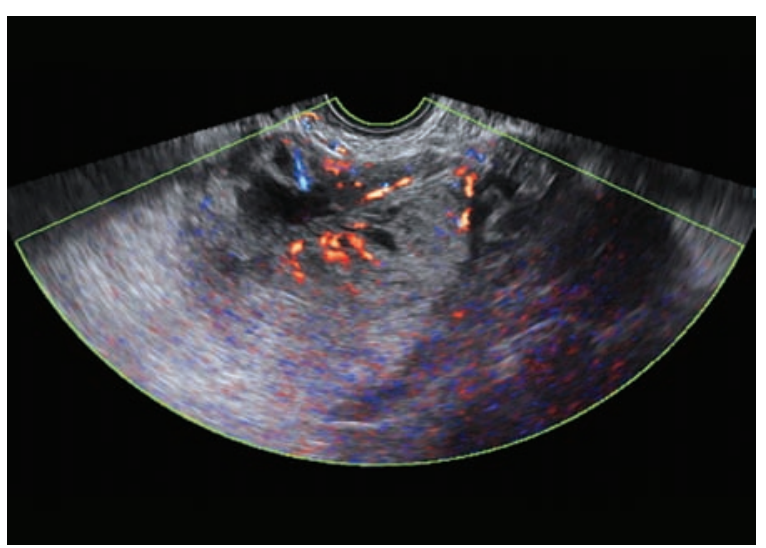

Fig. 44: Two-dimensional HD-flow image of a mucinous cystadenocarcinoma stage Ic in a 47-year-old woman

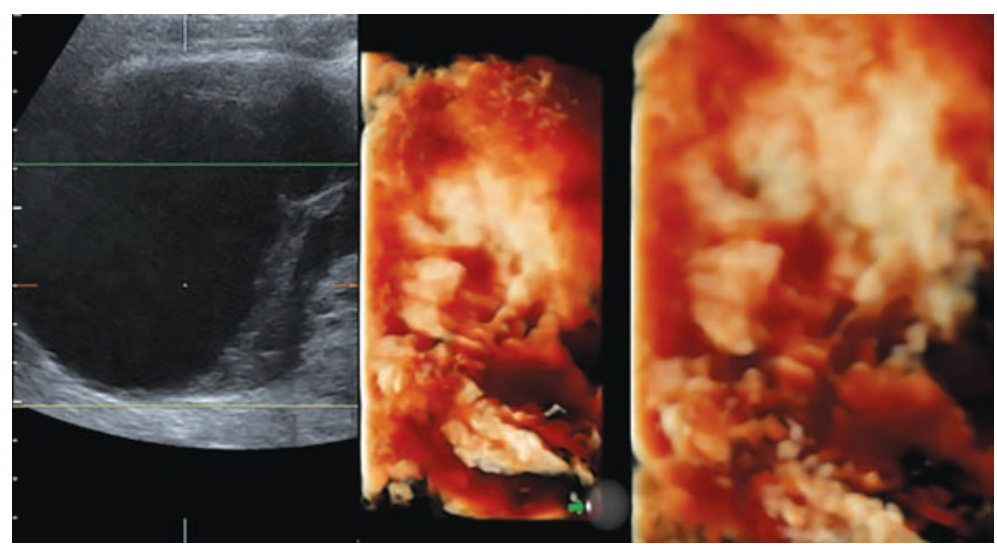

Fig. 45: Transabdominal HDlive images of a mucinous cystadenocarcinoma stage Ic in a 47-year-old woman
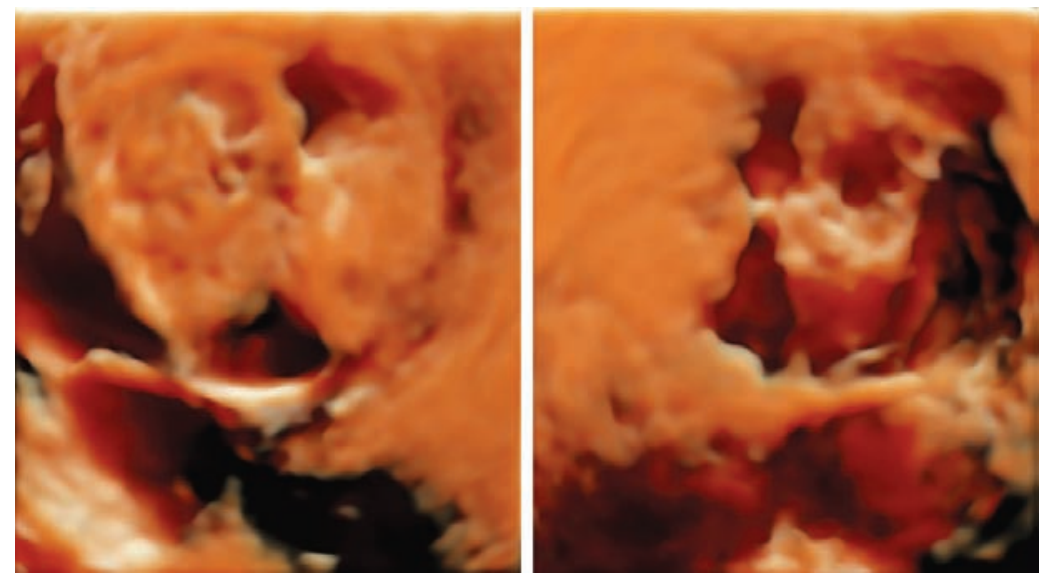

Fig. 46: Transvaginal HDlive images of a mucinous cystadenocarcinoma stage Ic in a 47-year-old woman

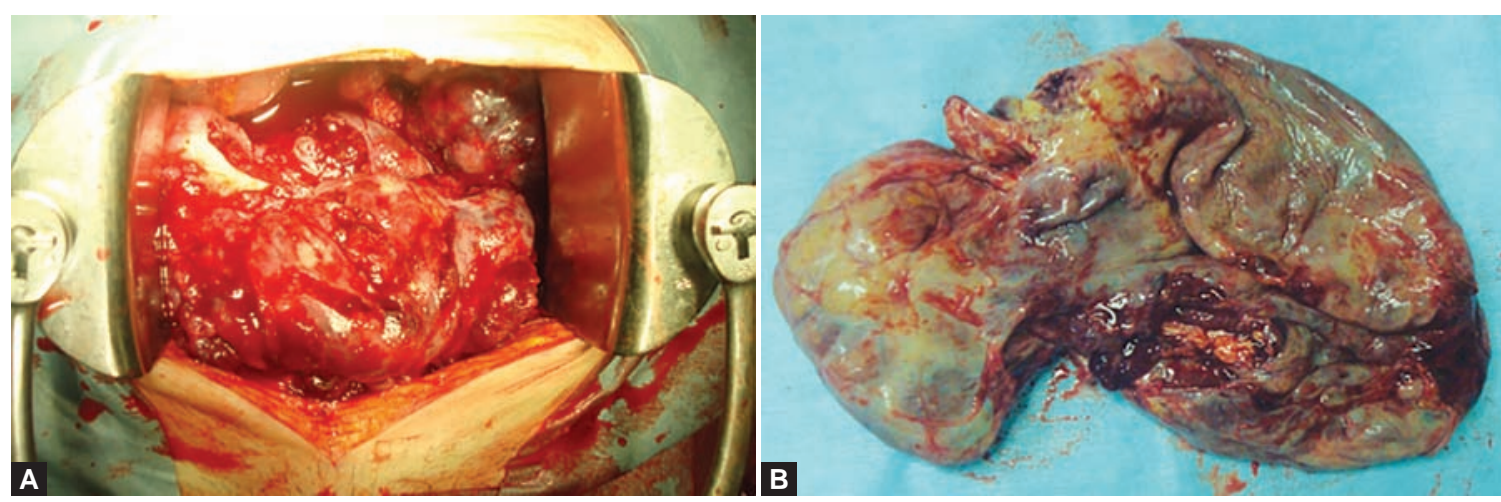

Figs 47A and B: Mucinous cystadenocarcinoma stage Ic: (A) During operation and (B) gross specimen

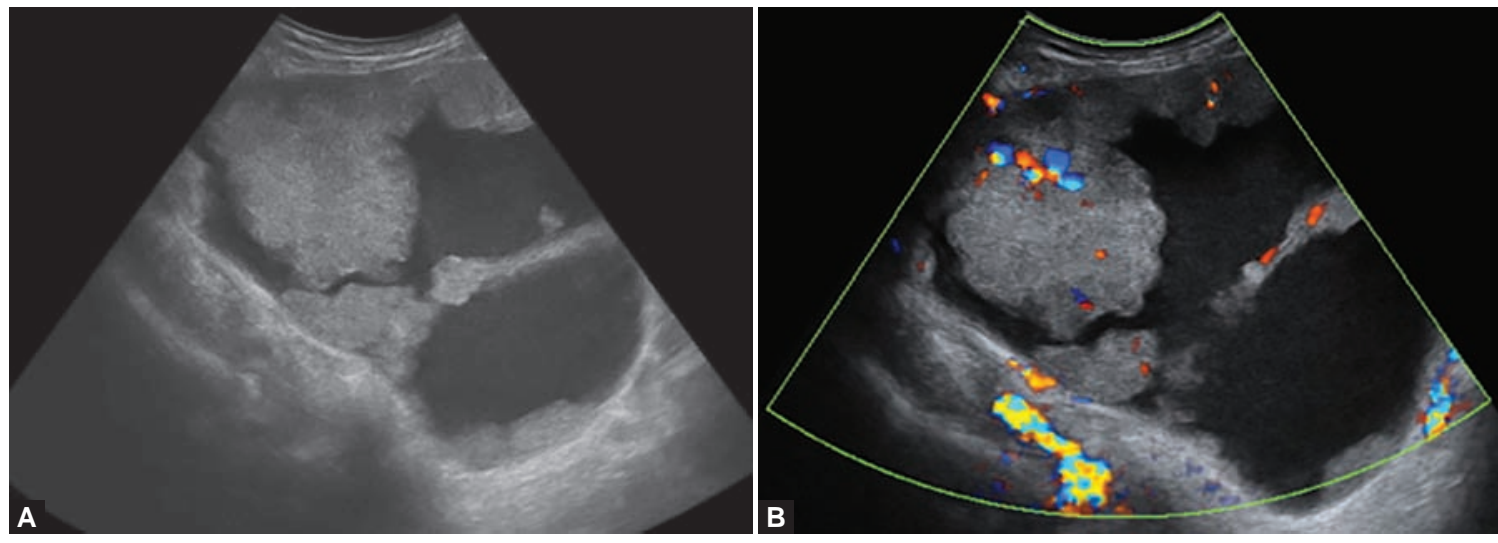

Figs 48A and B: Two-dimensional sonographic (A) and color Doppler ultrasound images (B) of a malignant mixed epithelial tumor stage IIIc (Courtesy: Reprinted with permission from Hata T et al) ${ }^{6}$ 

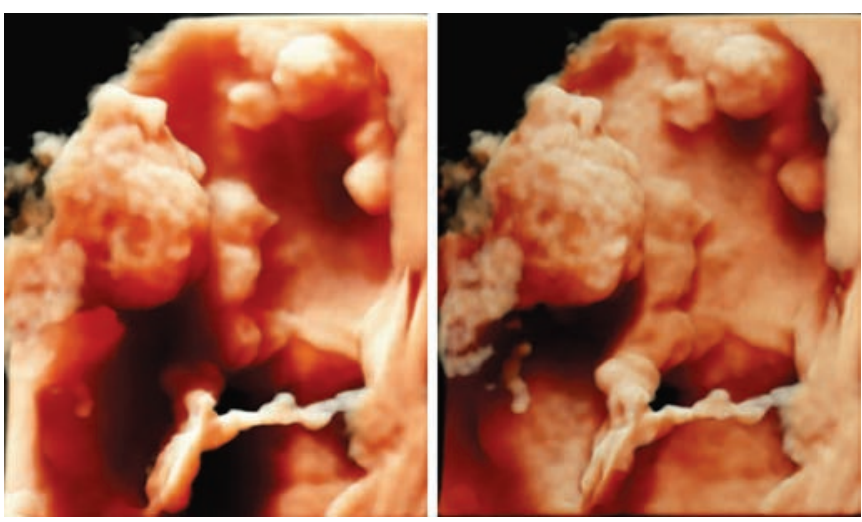

Fig. 49: HDlive images with different light sources of a malignant mixed epithelial tumor stage IIIc (Courtesy: Reprinted with permission from Hata $\mathrm{T}$ et al) ${ }^{6}$

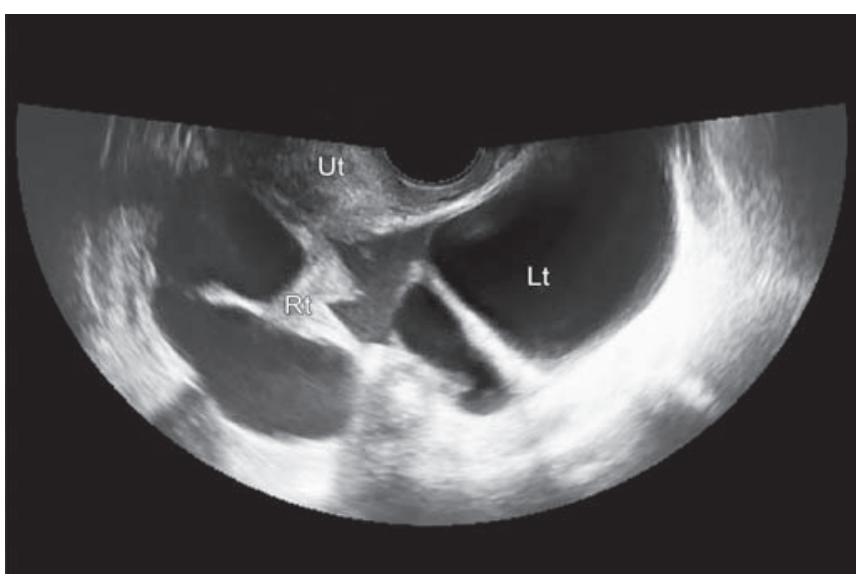

Fig. 51: Two-dimensional transvaginal sonographic image of bilateral hydrosalpinx (Lt: Left fallopian tube; Rt: Right fallopian tube; Ut: Uterus) (Courtesy: Reprinted with permission from Hata T et al) ${ }^{6}$

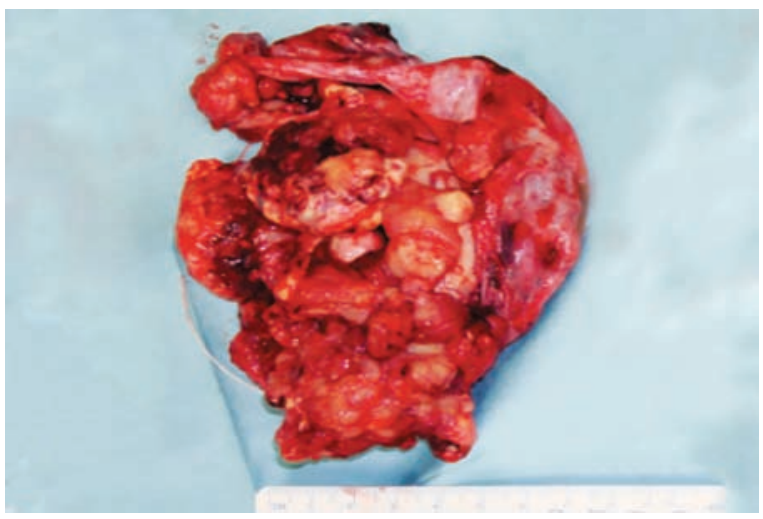

Fig. 50: Macroscopic specimen of a malignant mixed epithelial tumor stage IIIc (Courtesy: Reprinted with permission from Hata T et al) ${ }^{6}$

\section{Hydrosalpinx}

With 2D sonography, bilateral hydrosalpinx appears as cystic lesions, sonoluscent with multiple incomplete septations, and adherent to the uterus (Fig. 51). ${ }^{6}$ 3D power Doppler depicts the absence of blood flow in the right tube compared to the left tube due to torsion of the right tube (Fig. 52). The HDlive inversion mode shows the contents of the dilated lumen (Fig. 53). The 'snowstorm appearance' depicted on HDlive of the right tube is the thickened debris caused by necrosis, brought about by the twisted tube, while the left tube has a clear and smooth surface (Fig. 54). A dark red-colored right tube and fresh red-colored left tube were seen during the operation (Fig. 55).

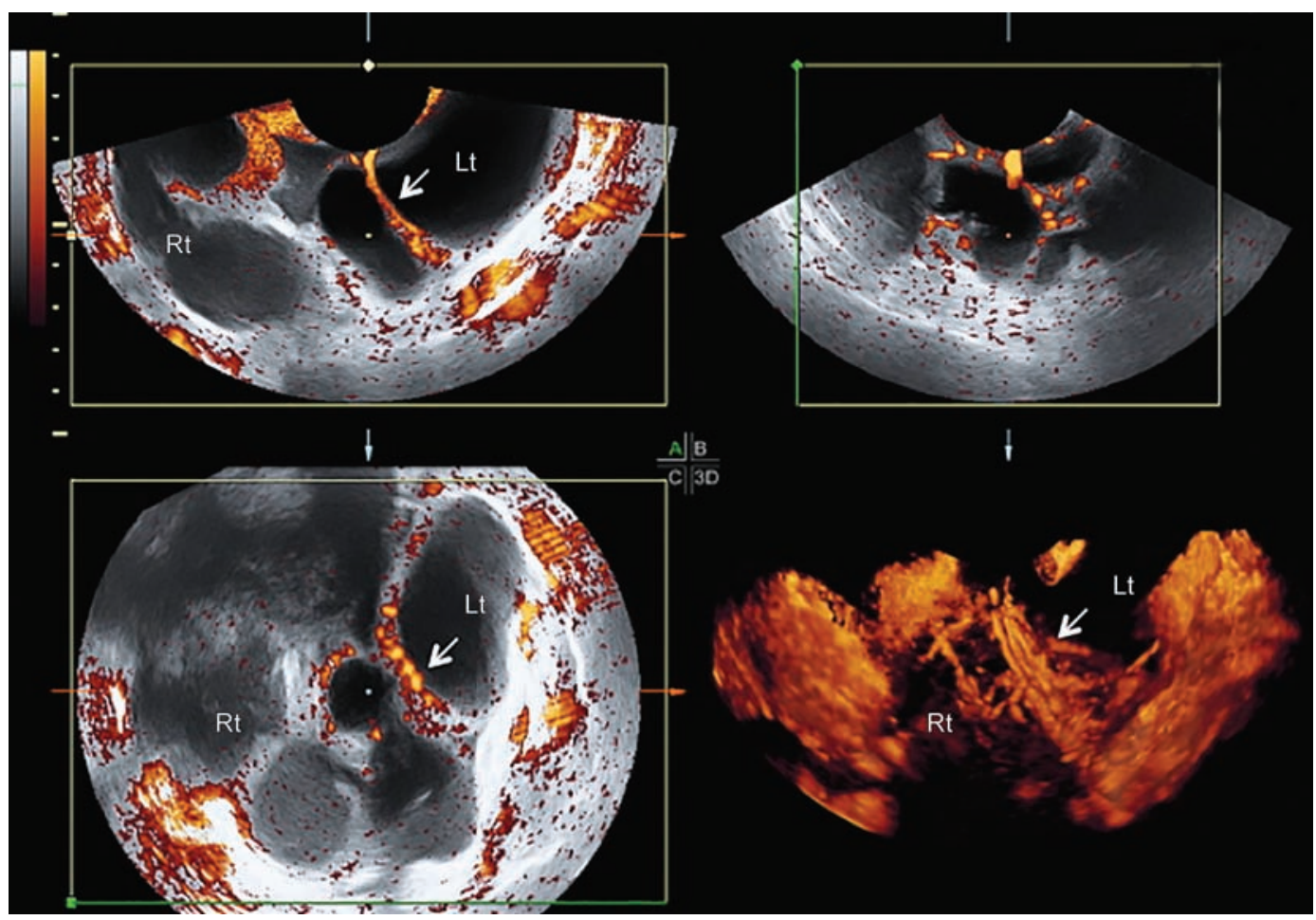

Fig. 52: Three-dimensional power Doppler ultrasound image of bilateral hydrosalpinx (Lt: Left fallopian tube; Rt: Right fallopian tube). Arrow shows presence of abundant blood flow in the left tube compared to the right tube, with no flow 

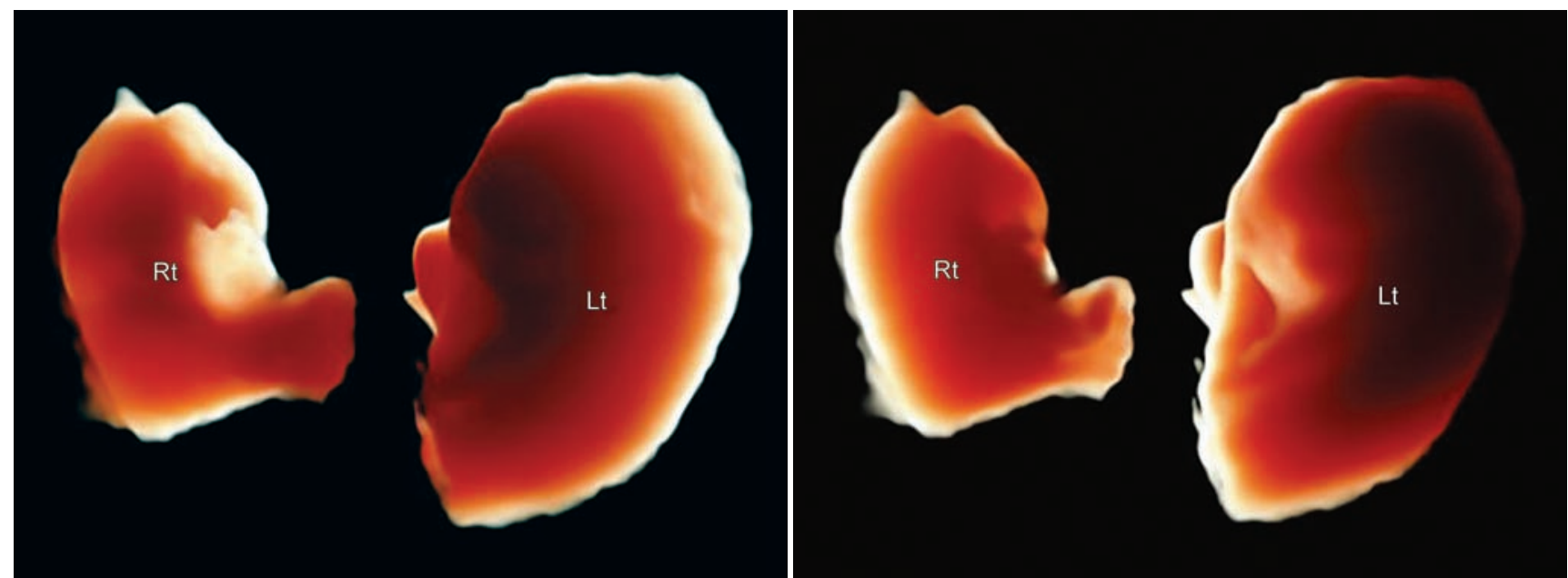

Fig. 53: HDlive inversion mode images with different light sources of bilateral hydrosalpinx (Lt: Left fallopian tube; Rt: Right fallopian tube)

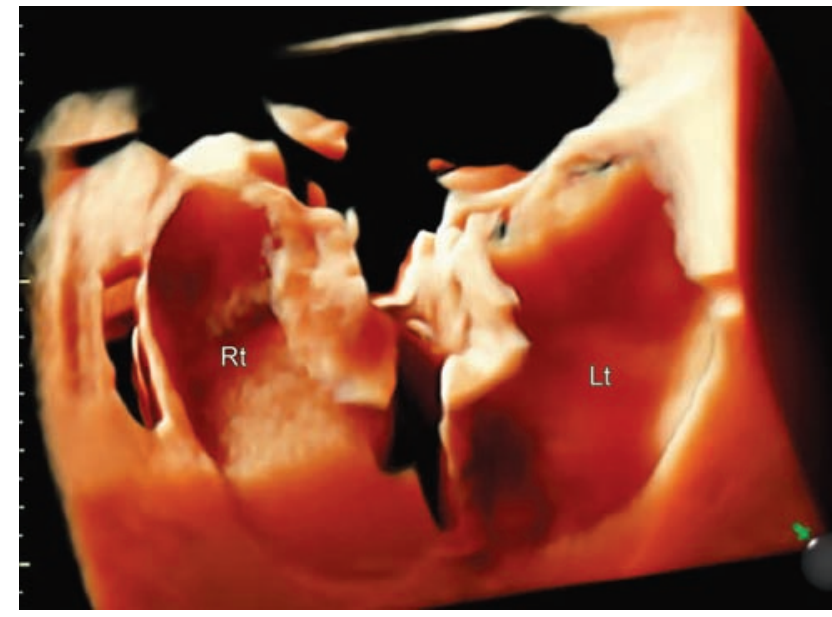

Fig. 54: HDlive image of bilateral hydrosalpinx. Notice the 'snow storm pattern' on the right fallopian tube (Rt), which is an exudate due to necrosis of the twisted tube (Lt: Left fallopian tube)

\section{CONCLUSION}

The use of HDlive improves the sonographic features of gynecologic tumors evaluated initially using 2D sonography. In uterine tumors, localization of the lesions is clearly depicted. The endometrial cavity and its contents are well visualized. The adjustable light source of HDlive gives the operator the ability to appreciate minute details of the lesions at different angles. In ovarian tumors, diagnosis based on 'pattern recognition' employing 2D sonography is enhanced using HDlive. Realistic features of the inner tumor content are clearly shown, and it is very similar to the macroscopic specimen. Differentiation of a benign from malignant tumor is also possible using HDlive. In fallopian tube disorders, bilateral hydrosalpinx with a twisted right tube diagnosed using HDlive shows remarkable features, such as a 'snow storm pattern', which represents exudate from necrosis of the twisted tube. The accurate characterization of gynecologic tumors is important in terms of management

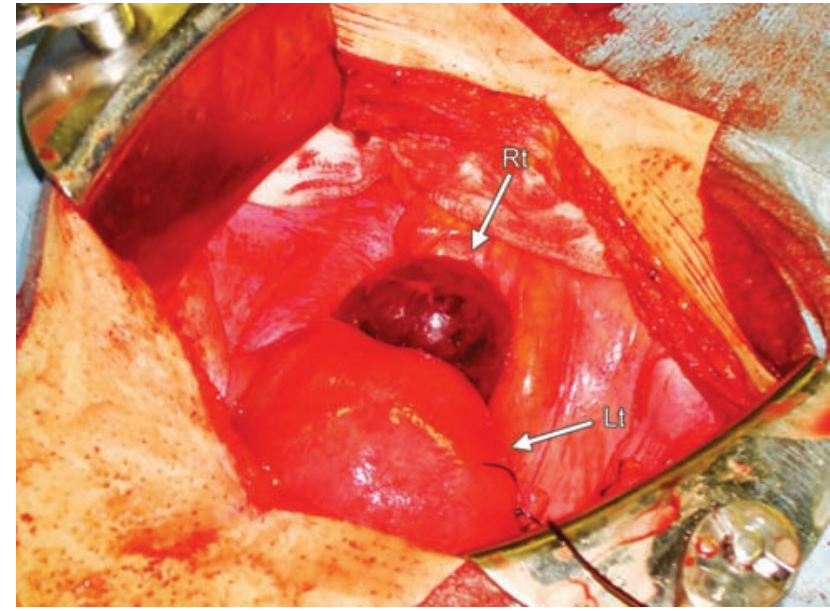

Fig. 55: Bilateral hydrosalpinx during operation (Lt: Left fallopian tube; Rt: Right fallopian tube)

options. Realistic features on HDlive give an advantage in the early diagnosis of tumors and options for more appropriate treatment. HDlive should be a valuable tool in adjunct to other imaging modalities for an accurate preoperative diagnosis.

\section{ACKNOWLEDGMENTS}

The work reported in this paper was supported by a Grant-in-Aid for Scientific Research on Innovative Areas 'Constructive Developmental Science' (No. 24119004), and a Research Grant (No. 25462561) from The Ministry of Education, Culture, Sports, Science and Technology, Japan.

\section{REFERENCES}

1. Hata T. HDlive rendering image at 6 weeks of gestation. J Med Ultrasonics 2013;40(4):495-496.

2. Hata T, Hanaoka U, Tenkumo C, Sato M, Tanaka H, Ishimura M. Three- and four-dimensional HDlive rendering images of normal and abnormal fetuses: pictorial essay. Arch Gynecol Obstet 2012;286(6):1431-1435. 
3. Hata T, Hanaoka U, Mashima M. HDlive rendering image of cyclopia and a proboscis in a fetus with normal chromosomes at 32 weeks of gestation. J Med Ultrasonics 2014;41(1):109-110.

4. Hata T, Uketa E, Tenkumo C, Hanaoka U, Kanenishi K, Tanaka H. Three- and four-dimensional HDlive rendering image of fetal acrania/exencephaly in early pregnancy. J Med Ultrasonics 2013;40(3):271-273.

5. Hanaoka U, Tanaka H, Koyano K, Uematsu R, Kanenishi K, Hata T. HDlive imaging of the face of fetuses with autosomal trisomies. J Med Ultrasonics 2014;41(3):339-342.

6. Hata T, Kanenishi K, Mashima M, Nitta E, Mori N, Hanaoka U, Tanaka H. HDlive rendering image of adnexal tumors: preliminary report. J Med Ultrasonics 2014;41(2):181-186.

7. Grigore M. HDlive of a serous borderline ovarian tumor. Ultrasound Obstet Gynecol 2013;41(5):598-599.

8. Kirk E, Papageorghiou AT, Condous G, Bottomley C, Bourne T. The accuracy of first-trimester ultrasound in the diagnosis of hydatidiform mole. Ultrasound Obstet Gynecol 2007;29(1):70-75.

9. Cajusay-Velasco S, Kanenishi K, Mashima M, Nishizawa C, Kawada K, Hata T. HDlive and HD-flow images of early-stage nonhydropic mole. J Med Ultrasonics 2014;41(4):507-509.

10. Mavrelos D, Ben-Nagi J, Holland T, Hoo W, Naftalin J, Jurkovic D. The natural history of fibroids. Ultrasound Obstet Gynecol 2010;35(2):238-242.

11. Oliva E. Cellular mesenchymal tumors of the uterus: a review emphasizing recent observations. Int J Gynecol Pathol 2014;33(4):374-384.
12. Bonilla-Musoles F, Raga F, Osborne N. Three-dimensional ultrasound evaluation of ovarian masses. Gynecol Oncol 1995;59(1):129-135.

13. Hata T, Hata K, Noguchi J, Kanenishi K, Shiota A. Ultrasound for the evaluation of adnexal malignancy: From 2D to 3D ultrasound. J Obstet Gynaecol Res 2011;37(10):1255-1268.

14. Hata T, Yanagihara T, Hayashi K, Yamashiro C, Ohnishi Y, Akiyama M, Manabe A, Miyakazi K. Three-dimensional ultrasonographic evaluation of ovarian tumors: a preliminary study. Hum Reprod 1999;14(3):858-861.

15. Alcazar JL, Garcia-Manero M, Galvan R. Three-dimensional sonographic morphologic assessment of adnexal masses. J Ultrasound Med 2007;26(8):1007-1011.

16. Zalud I, Busse R, Kurjak BF. Asymptomatic simple ovarian cyst in postmenopausal women: syndrome of "visible ovary". Donald School J Ultrasound Obstet Gynecol 2013;7(2):182-186.

17. Van Holsbeke C, Van Calster B, Guerriero S, Savelli L, Palastine D, Zissoni AA, Czekierdowski A, Fisherova D, Zhang J, Mestdagh G, et al. Endometriomas: their ultrasound characteristics. Ultrasound Obstet Gynecol 2010;35(6):730-740.

18. Hoo WL, Yazbek J, Holland T, Mavrelos D, Tong ENC, Jurkovic D. Expectant management of ultrasonically diagnosed ovarian dermoid cyst: is it possible to predict outcome? Ultrasound Obstet Gynecol 2010;36(2):235-240.

19. Lee EJ, Joo HJ, Ryu HS. Malignant mixed mullerian tumor of the uterus: Sonographic spectrum. Ultrasound Obstet Gynecol 2012;39(3):348-353. 